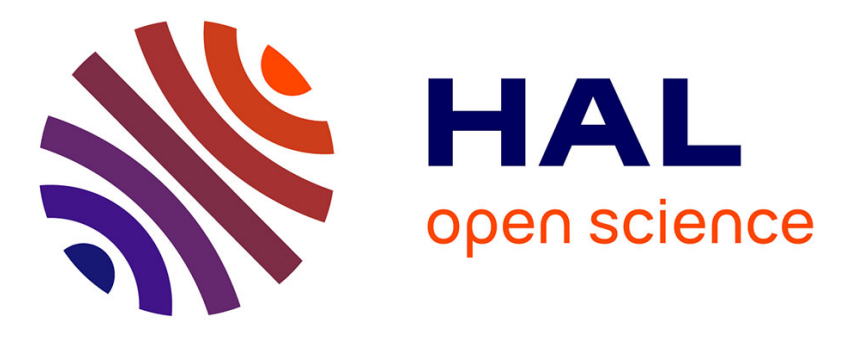

\title{
Model-based fault diagnosis for aerospace systems: a survey
}

Julien Marzat, Hélène Piet-Lahanier, Frédéric Damongeot, Eric Walter

\section{To cite this version:}

Julien Marzat, Hélène Piet-Lahanier, Frédéric Damongeot, Eric Walter. Model-based fault diagnosis for aerospace systems: a survey. Proceedings of the Institution of Mechanical Engineers, Part G: Journal of Aerospace Engineering, 2012, 226 (10), pp 1329-1360. 10.1177/0954410011421717 . hal00615617

\section{HAL Id: hal-00615617 \\ https://hal-centralesupelec.archives-ouvertes.fr/hal-00615617}

Submitted on 9 Jan 2012

HAL is a multi-disciplinary open access archive for the deposit and dissemination of scientific research documents, whether they are published or not. The documents may come from teaching and research institutions in France or abroad, or from public or private research centers.
L'archive ouverte pluridisciplinaire HAL, est destinée au dépôt et à la diffusion de documents scientifiques de niveau recherche, publiés ou non, émanant des établissements d'enseignement et de recherche français ou étrangers, des laboratoires publics ou privés. 


\title{
Proceedings of the Institution of Mechanical Engineers, Part G: Journal of Aerospace Engineering
}

\author{
Model-based fault diagnosis for aerospace systems: a survey \\ $J$ Marzat, $\mathrm{H}$ Piet-Lahanier, F Damongeot and E Walter \\ Proceedings of the Institution of Mechanical Engineers, Part G: Journal of Aerospace Engineering published online 6 \\ January 2012 \\ DOI: $10.1177 / 0954410011421717$
}

The online version of this article can be found at:

http://pig.sagepub.com/content/early/2012/01/06/0954410011421717

\author{
Published by: \\ (S)SAGE \\ http://www.sagepublications.com
}

On behalf of:

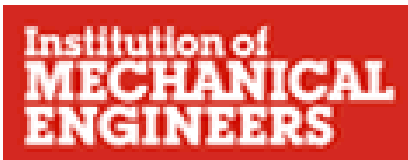

Institution of Mechanical Engineers

Additional services and information for Proceedings of the Institution of Mechanical Engineers, Part G: Journal of Aerospace Engineering can be found at:

Email Alerts: http://pig.sagepub.com/cgi/alerts

Subscriptions: http://pig.sagepub.com/subscriptions

Reprints: http://www.sagepub.com/journalsReprints.nav

Permissions: http://www.sagepub.com/journalsPermissions.nav

>> Proof - Jan 6, 2012

What is This? 


\title{
Model-based fault diagnosis for aerospace systems: a survey
}

\author{
J Marzat $^{1,2 *}$, H Piet-Lahanier ${ }^{1}$, F Damongeot ${ }^{1}$, and E Walter ${ }^{2}$ \\ ${ }^{1}$ ONERA - The French Aerospace Laboratory, Palaiseau, France \\ ${ }^{2}$ CNRS-SUPELEC, Univ Paris-Sud, Gif-Sur-Yvette, France
}

The manuscript was received on 25 May 2011 and was accepted after revision for publication on 8 August 2011.

DOI: $10.1177 / 0954410011421717$

\begin{abstract}
This survey of model-based fault diagnosis focuses on those methods that are applicable to aerospace systems. To highlight the characteristics of aerospace models, generic nonlinear dynamical modelling from flight mechanics is recalled and a unifying representation of sensor and actuator faults is presented. An extensive bibliographical review supports a description of the key points of fault detection methods that rely on analytical redundancy. The approaches that best suit the constraints of the field are emphasized and recommendations for future developments in in-flight fault diagnosis are provided.
\end{abstract}

Keywords: aerospace systems, aircraft, analytical redundancy, fault diagnosis, fault detection and isolation, flight control systems, health monitoring, non-linear systems

\section{INTRODUCTION}

According to a reliability study conducted by the US Office of the Secretary of Defense [1] , about 80 per cent of flight incidents concerning unmanned aerial vehicles (UAV) are due to faults affecting propulsion, flight control surfaces, or sensors. To allow autonomous aerial vehicles to continue their missions, there is an absolute necessity to identify unexpected changes (faults) in the system before they lead to a complete breakdown (failure).

Classically, hardware redundancy - multiple sensors or actuators with the same function - and simple thresholding were used to address fault detection [2]. Even if these techniques remain widespread in the aerospace industry $[\mathbf{3}, \mathbf{4}]$, the additional costs and weights they imply are an impediment to autonomy, especially for small and military autonomous vehicles. There is, therefore, the need to call upon analytical redundancy, i.e. to exploit mathematical relations between measured or estimated variables in order to detect possible dysfunctions. The resulting

${ }^{*}$ Corresponding author: ONERA - The French Aerospace Laboratory, F-91761 Palaiseau, France.

Email: julien.marzat@onera.fr set of methods is commonly called model-based, where model should be understood as a knowledgebased dynamical model, usually a set of differential equations in state-space form. Many methods have been proposed to address model-based fault diagnosis, an overview of which can be obtained from reference textbooks [5-12] and survey papers [13-26].

Emphasis will be put in this article on those modelbased quantitative methods that have been used for aerospace applications. Relatively, few books and survey papers have been published on this aspect of fault diagnosis [27-34]. The survey proposed here is supported by a large collection of references dealing with fault detection for flight systems. Papers are sorted according to the type of vehicle considered and a classification is proposed relating the fault diagnosis methods employed to each category of aerospace model. This should offer a better viewpoint on current research in the domain.

This article is organized as follows. Fault diagnosis terminology and concepts are briefly recalled in section 2, along with the typical architecture of modelbased theory. The main characteristics of flight control systems are highlighted in section 3. In particular, typical sensors and actuators are identified, and models of faults that can affect them are given. The 
common mathematical modelling of flight dynamics is also recalled, as it is the basis of dynamical models for fault diagnosis. Section 4 associates fault detection methods with their aerospace applications. The main principles of residual generation methods are recalled and references are provided for further investigation. Section 5 addresses details about residual evaluation strategies, i.e. thresholding and statistical tests. A concluding discussion on this comprehensive survey is given in section 6 to describe the state of the art in actual academic and industrial applications, to highlight the most promising approaches and to supply recommendations for future developments.

Specialists in aerospace engineering will access a self-contained overview of applicable fault detection and isolation (FDI) methods through sections 2, 4, and 5, while specialists in FDI looking for applications and benchmarks will find a generic modelling of aerospace systems and faults affecting their devices in section 3. Finally, this presentation may facilitate interaction between users of different FDI approaches on various flight systems, with special help from Table 4 and section 6 .

\section{BASICS OF FDI}

\subsection{Terminology}

Initially proposed by the IFAC SAFEPROCESS Technical Committee [35] and reproduced in Appendix B of reference [7], the following terminology is now standard in the fault diagnosis community.

A fault is an unpermitted deviation of at least one characteristic property or parameter of the system from acceptable/usual/standard conditions. A fault may lead to a failure, which is a permanent interruption of the system ability to perform a required function under specified operating conditions.

Fault detection is the determination of the presence of faults in a system and of their times of occurrence.It is generally followed by fault isolation to determine the type and location of the faults. Fault identification (or estimation) aims then at determining the size and time-varying behaviour of the faults. The complete process is usually called either FDI or fault detection and diagnosis (FDD), the latter including identification. These tasks generally involve the generation of residuals, which are fault indicators based on deviation between measurements and model-based computations. Residuals should remain small as long as there is no fault, and become sufficiently large to be noticeable whenever faults occur.
Once a fault has been detected, a natural idea is to try to compensate for it by modifying the control law of the flight vehicle considered. This is what fault tolerant control (FTC), or reconfiguration, is concerned with. The interested reader can refer to [25] for a survey of active FTC, which means that the design of the reconfiguration is based on FDI information while passive reconfiguration uses only robust control. FTC is a field in its own right, which will be left aside in this survey to focus exclusively on FDI.

\subsection{Types of faults}

Three types of faults are generally distinguished, according to the part of the system they affect.

1. A sensor fault is an abnormal variation in measurements, e.g. a systematic error abruptly affecting the value provided by an accelerometer.

2. An actuator fault is a malfunction on a device acting on the system dynamics, e.g. the lockingin-place of a flight control surface.

3. Process faults are changes in the inner parameters of the system that modify its dynamics, such as an unmodelled change in aerodynamic coefficients.

The general time-behaviour of a fault is inherently unpredictable and changes may be abrupt (involving discontinuities), incipient (gradual), or intermittent the latter two being the most challenging to detect. Further details on fault modelling and more examples for aerospace applications are given in section 3.2.

\subsection{Architecture of model-based methods}

Fault diagnosis is typically achieved by combining a residual generator and a residual evaluation strategy to provide Boolean decisions on whether faults have occurred. This sequence is illustrated in Fig. 1.

Residual generation uses a model of the system in which the control inputs sent to the actuators and the system outputs as measured by the sensors are injected to predict the behaviour of the system (or part of it) and compare this prediction to the actual behaviour. The aim of this procedure is to compute quantitative indices of the presence of faults, the residuals. Much effort has been devoted to the design of methods for residual generation (sections 4.2 to 4.6), since this task is at the heart of model-based FDI.

The residuals should be close to zero in fault-free condition and deviate from zero after the occurrence of faults to which they are sensitive. There is the need for a residual evaluation strategy that automatically translates the time-behaviour of a residual into a Boolean decision function, indicating whether each signal is to be considered as small or not (section 5). 


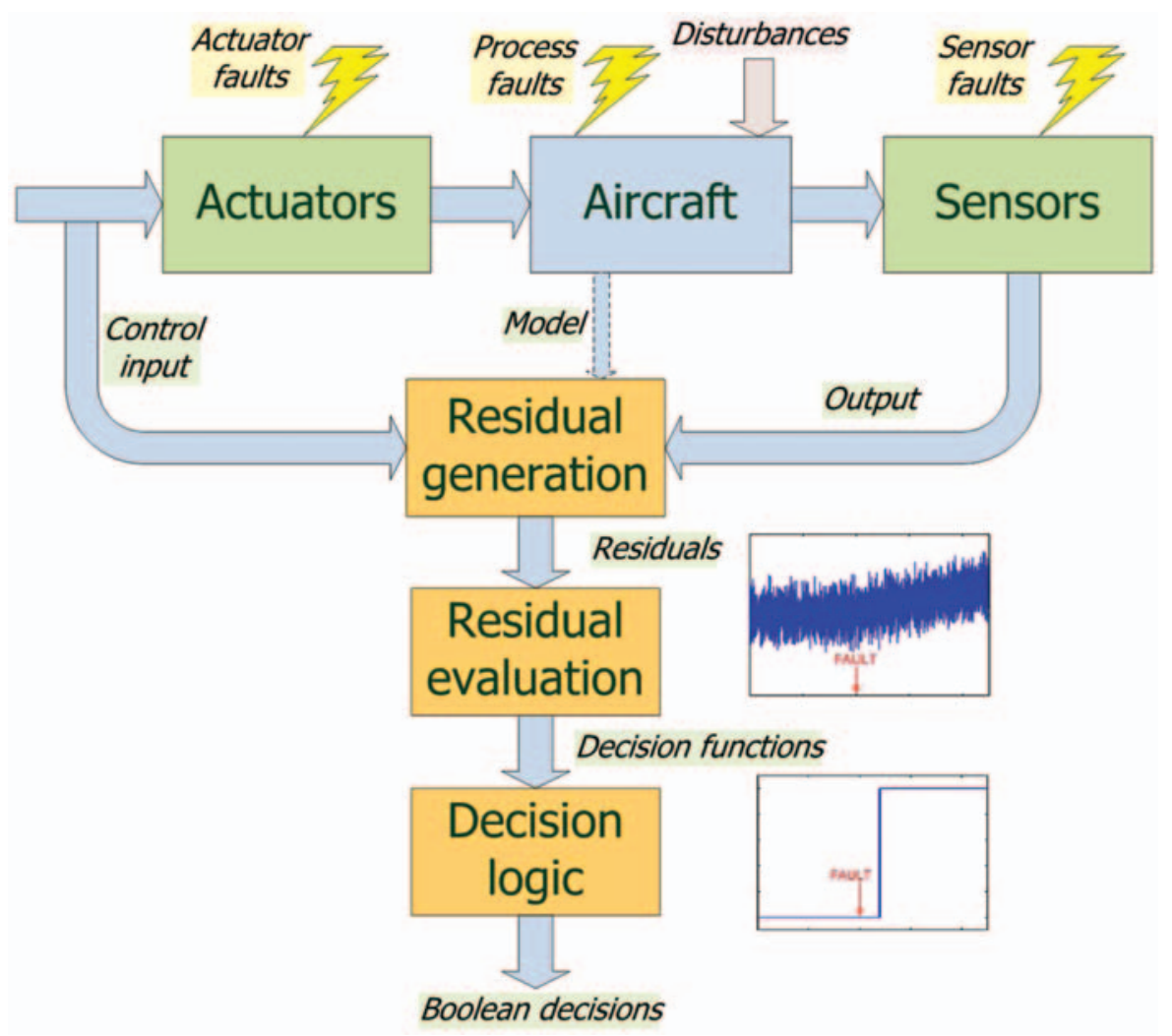

Fig. 1 Typical FDI scheme

This generally involves the choice of thresholds or tests of statistical hypotheses.

Any given residual may be sensitive to one fault only, to all the faults, or to an intermediate number of faults. This is why a decision logic following residual evaluation may be needed to transform the collection of decision functions into actual fault isolation.

\subsection{FDI performance and robustness issues}

An adequate tuning of an FDI procedure should lead to a satisfactory trade-off between the contradictory objectives of minimizing the rates of non-detection (missing a fault) and false-alarm (raising an alarm in fault-free condition). To evaluate any given Boolean decision function, quantitative indices measuring FDI performance can be defined [36]. Figure 2 shows time zones in the evolution of a Boolean decision function that are the basis of the definition of these indices. The value of the function before $t_{\mathrm{on}}$ and after $t_{\text {hor }}$ is not to be taken into account, while $t_{\text {from }}$ is the instant at which the fault occurs (known in simulation but not in actual operation).

Assuming that the fault is persistent, one can define the following indices to evaluate fault-detection performance.

1. The detection delay $t_{\mathrm{dt}}$ is the time elapsed between the fault-occurrence time $t_{\text {from }}$ and the last instant

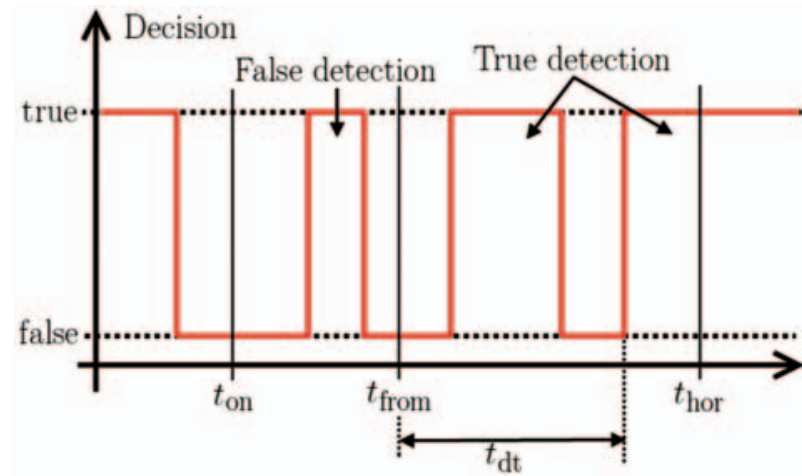

Fig. 2 Time zone parameters for the definition of performance indices

of time at which the decision signal switched from false to true.

2. The false-detection rate $r_{\mathrm{fd}}=\left(\sum_{i} t_{\mathrm{fd}}^{i}\right) /\left(t_{\mathrm{from}}-t_{\mathrm{on}}\right)$, where $t_{\mathrm{fd}}^{i}$ is the $i$ th period of time between $t_{\mathrm{on}}$ and $t_{\text {from }}$ where the decision is true.

3 . The non-detection rate $r_{\mathrm{nd}}=1-r_{\mathrm{td}}$, where $r_{\mathrm{td}}=\left(\sum_{i} t_{\mathrm{td}}^{i}\right) /\left(t_{\mathrm{hor}}-t_{\text {from }}\right)$ is the true-detection rate with $t_{\mathrm{td}}^{i}$ the $i$ th period of time between $t_{\text {from }}$ and $t_{\mathrm{hor}}$ where the decision is true.

Similar indices can be defined to quantify performance of fault isolation, by considering each decision function or group of decision functions associated to 
the detection of a particular fault [36]. Relative computational cost and easiness of tuning should also be taken into account in the global assessment of a FDI approach.

Various sources of uncertainty may be present and disturb diagnosis accuracy, since the model of the system is not a perfect reflection of reality. The existence of measurement noise, model uncertainty, and unmodelled exogenous disturbances should be taken into account during design. Robustness can indeed be supplied at different levels. On the one hand, an effort could be undertaken to generate residuals that are decoupled, as far as possible, from measurement noise and unknown inputs (disturbances and other faults) and robust to model uncertainty. On the other hand, residual evaluation can embed statistical information to reduce the influence of noise on decision, while adaptive thresholds may try to compensate for unknown inputs [37].

\section{AEROSPACE MODELS FOR FDI}

FDI methods have been investigated for various types of aeronautical and space vehicles. A classification of papers according to the type of vehicle considered is

\subsection{Flight mechanics and mathematical modelling}

The rigid motion of a flight vehicle is mainly parametrized in two frames, namely the navigation and body frames. The navigation frame is attached to a fixed location at Earth's local tangent plane and oriented, e.g. north-east-down. It is then assumed to be a local inertial frame where Newton's laws of motion apply. The body frame has its origin at the centre of mass of the aircraft and its axes are, respectively oriented forward along the longitudinal axis, to the right along the lateral axis and downward [157-160].

\subsubsection{Kinematics}

Denote the position of a vehicle in the inertial frame by $\mathbf{x}_{\mathrm{m}}=[x, y, z]^{\mathrm{T}}$ and its position in the body frame by $\mathbf{x}_{\mathrm{bm}}=\left[\begin{array}{ll}x_{\mathrm{b}}, & y_{\mathrm{b}}, z_{\mathrm{b}}\end{array}\right]^{\mathrm{T}}$. Velocities are then given by $\mathbf{v}_{\mathrm{m}}=[\dot{x}, \dot{y}, \dot{z}]^{\mathrm{T}}$ in the inertial frame and $\mathbf{v}_{\mathrm{bm}}=\left[\nu_{\mathrm{bx}}\right.$, $\left.v_{\mathrm{by}}, v_{\mathrm{bz}}\right]^{\mathrm{T}}$ in the body frame. The change of coordinates from inertial to body frames is governed by three Euler angles $[\varphi, \theta, \psi]^{\mathrm{T}}$, for roll, pitch and yaw respectively (Fig. 3). The kinematic transformation from $\mathbf{v}_{\mathrm{bm}}$ to $\mathbf{v}_{\mathrm{m}}$ thus involves the rotation matrix

$$
\left[\begin{array}{c}
\dot{x} \\
\dot{y} \\
\dot{z}
\end{array}\right]=\left[\begin{array}{ccc}
\cos \psi \cos \theta & -\sin \psi \cos \varphi+\cos \psi \sin \theta \sin \varphi & \sin \psi \sin \varphi+\cos \psi \sin \theta \cos \varphi \\
\sin \psi \cos \theta & \cos \psi \cos \varphi+\sin \psi \sin \theta \sin \varphi & -\cos \psi \sin \varphi+\sin \psi \sin \theta \cos \varphi \\
-\sin \theta & \cos \theta \sin \varphi & \cos \theta \cos \varphi
\end{array}\right] \cdot\left[\begin{array}{c}
v_{b x} \\
v_{b y} \\
v_{b z}
\end{array}\right]
$$

proposed in Table 1. Even if the characteristics and missions of aircraft mentioned are quite diverse, equipments and behaviours are similar. The aim of this section is thus to review the classical modelling of flight vehicles and their sensors and actuators for fault diagnosis. The sensors considered here are navigation sensors, which provide information on the state of the flying vehicle.
The roll, pitch, and yaw rates constitute the angular velocity vector $\boldsymbol{\omega}=[p, q, r]^{\mathrm{T}}$. Their projection in the body frame allows them to be expressed from the time derivatives of the Euler angles as

$$
\left[\begin{array}{l}
p \\
q \\
r
\end{array}\right]=\left[\begin{array}{ccc}
1 & 0 & -\sin \theta \\
0 & \cos \varphi & \cos \theta \sin \varphi \\
0 & -\sin \varphi & \cos \theta \cos \varphi
\end{array}\right]\left[\begin{array}{c}
\dot{\varphi} \\
\dot{\theta} \\
\dot{\psi}
\end{array}\right]
$$

Table 1 Classification of FDI papers based on the type of aircraft considered, with corresponding

\begin{tabular}{|c|c|c|c|}
\hline Aircraft model & References & Sensors & Actuators \\
\hline Small aircraft & {$[1,38-61]$} & IMU/INS, ADS & Ailerons, rudders, elevators, and propellers \\
\hline Rotorcraft & $\begin{array}{l}\text { Quadrotor: [62-67] } \\
\text { Helicopter: }[68-72]\end{array}$ & $\begin{array}{l}\text { IMU/INS, global positioning } \\
\text { system (GPS), barometer, } \\
\text { and radar }\end{array}$ & Rotors \\
\hline General civil aircraft & {$[2,3,32,73-107]$} & $\begin{array}{l}\text { IMU/INS, GPS, pitot probes, } \\
\text { and ADS }\end{array}$ & $\begin{array}{l}\text { Highly redundant ailerons, rudders, elevators, } \\
\text { and jet engines }\end{array}$ \\
\hline Fighter aircraft & $\begin{array}{l}\text { F-16: }[\mathbf{1 0 8}-119] \\
\text { Others: }[120-129]\end{array}$ & $\begin{array}{l}\text { IMU/INS, ADS, GPS, } \\
\text { barometer, and radar }\end{array}$ & Ailerons, rudders, elevators, canards, and jet engines \\
\hline Missile & {$[130-136]$} & IMU/INS, GPS, and radar & Rudders, elevators, and jet engines \\
\hline Rocket/reentry vehicle & {$[137-143]$} & IMU/INS, and ADS & Ailerons, rudders, elevators, and jet engines \\
\hline Spacecraft & {$[4,31,144-156]$} & IMU/INS, and star tracking & Thrusters and reaction wheels \\
\hline
\end{tabular}
typica sensors and actuators (acronyms are explained in main text) 


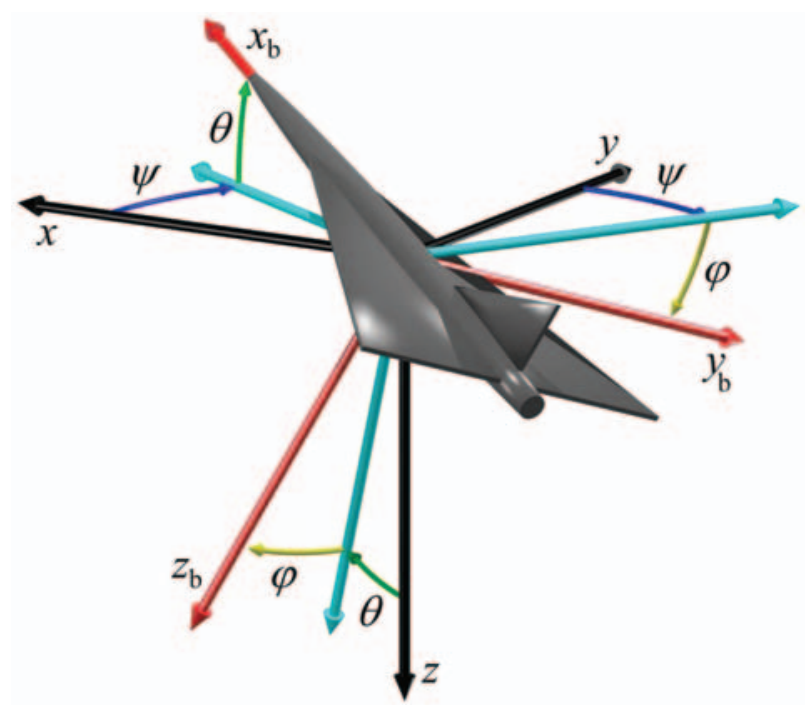

Fig. 3 Euler angles transforming inertial frame into body frame

which can be inverted as

$$
\left[\begin{array}{c}
\dot{\varphi} \\
\dot{\theta} \\
\dot{\psi}
\end{array}\right]=\left[\begin{array}{ccc}
1 & \sin \varphi \tan \theta & \cos \varphi \tan \theta \\
0 & \cos \varphi & -\sin \varphi \\
0 & \sin \varphi / \cos \theta & \cos \varphi / \cos \theta
\end{array}\right]\left[\begin{array}{l}
p \\
q \\
r
\end{array}\right]
$$

The kinematics equations (1) and (3) are part of the dynamical model of any vehicle from Table 1. Note that a quaternion may also be used instead of the three Euler angles to manage the coordinate transformation; in this case the rotation matrix in (1) would be expressed with the four components of the quaternion and (3) would become a relation between the quaternion time-derivative and angular velocity $[158,159]$. The overall structure of the model would remain the same, with one additional state variable.

\subsubsection{Dynamics}

Force and momentum equations are needed to complete the dynamical model of aeronautical systems, since the relations established so far do not involve control inputs. In the body frame, the force equation takes the form

$$
\left[\begin{array}{c}
\dot{\nu}_{\text {bx }} \\
\dot{v}_{\text {by }} \\
\dot{v}_{\text {bz }}
\end{array}\right]=\frac{1}{m}\left(\mathbf{f}_{\text {aero }}+\mathbf{f}_{\mathrm{g}}+\mathbf{f}_{\text {prop }}\right)-\left[\begin{array}{c}
p \\
q \\
r
\end{array}\right] \times\left[\begin{array}{c}
v_{\text {bx }} \\
v_{\text {by }} \\
v_{\text {bz }}
\end{array}\right]
$$

where $\mathbf{f}_{\mathrm{g}}$ is the gravitational force, $\mathbf{f}_{\text {prop }}$ the propulsion force (depending on the type of propulsion device), and $\mathbf{f}_{\text {aero }}$ the aerodynamic force. The expression of $\mathbf{f}_{g}$ is always

$$
\mathbf{f}_{\mathrm{g}}=m g\left[\begin{array}{c}
-\sin \theta \\
\cos \theta \sin \varphi \\
\cos \theta \cos \varphi
\end{array}\right]
$$

where the mass $m$ and gravity $g$ are not necessarily constant. The structure of $\mathbf{f}_{\text {aero }}$ may vary according to the type and configuration of the actuators. It can be written for most of aeronautical applications as

$$
\mathbf{f}_{\text {aero }}=Q s_{\text {ref }}\left[\begin{array}{l}
c_{\mathrm{x}}(\alpha, \beta, V, \mathbf{u}) \\
c_{\mathrm{y}}(\alpha, \beta, V, \mathbf{u}) \\
c_{\mathrm{z}}(\alpha, \beta, V, \mathbf{u})
\end{array}\right]
$$

where the aerodynamic coefficients $c_{(\cdot)}$ are non-linear functions and $\mathbf{u}$ the vector of control inputs translating the actuator positions. The velocity norm $V$ and dynamic pressure $Q$ are given by

$$
\begin{aligned}
V & =\sqrt{v_{\mathrm{bx}}^{2}+v_{\mathrm{by}}^{2}+v_{\mathrm{bz}}^{2}} \\
Q & =\frac{1}{2} \rho V^{2}
\end{aligned}
$$

and typical expressions for the angle of attack $\alpha$ and the sideslip angle $\beta$ are

$$
\begin{aligned}
& \alpha=\arctan \left(\frac{v_{\mathrm{bz}}}{v_{\mathrm{bx}}}\right) \\
& \beta=\arctan \left(\frac{\nu_{\mathrm{by}}}{v_{\mathrm{bx}}}\right)
\end{aligned}
$$

Especially in civil aviation, the time derivatives of (7), (9), and (10) are sometimes used instead of (4) to characterize the translational dynamics of aircraft.

The momentum equation is

$$
\left[\begin{array}{c}
\dot{p} \\
\dot{q} \\
\dot{r}
\end{array}\right]=\mathbf{I}^{-1}\left(\left[\begin{array}{c}
L_{\text {naero }}+L_{\text {aero }} \\
M_{\text {naero }}+M_{\text {aero }} \\
N_{\text {naero }}+N_{\text {aero }}
\end{array}\right]-\left[\begin{array}{c}
p \\
q \\
r
\end{array}\right] \times\left(\mathbf{I} \cdot\left[\begin{array}{c}
p \\
q \\
r
\end{array}\right]\right)\right)
$$

where the inertia matrix I may have some terms equal to zero, depending on the geometry of the aircraft. The models of aerodynamic moments $L_{\text {aero }}, M_{\text {aero, }}$, $N_{\text {aero }}$ have an expression similar to the components of $\mathbf{f}_{\text {aero }}$

$$
\left[\begin{array}{c}
L_{\text {aero }} \\
M_{\text {aero }} \\
N_{\text {aero }}
\end{array}\right]=Q s_{\text {ref }} l_{\text {ref }}\left[\begin{array}{c}
c_{1}(\alpha, \beta, V, \omega, \mathbf{u}) \\
c_{\mathrm{m}}(\alpha, \beta, V, \omega, \mathbf{u}) \\
c_{\mathrm{n}}(\alpha, \beta, V, \omega, \mathbf{u})
\end{array}\right]
$$

where the aerodynamic coefficients $c_{(\cdot)}$ are non-linear functions. The moments $L_{\text {naero, }}, M_{\text {naero, }}$ and $N_{\text {naero }}$ are very much case-dependent, and may contain propulsion moments.

\subsubsection{State-space model}

A dynamical state-space model can be obtained by considering a state vector consisting of the position 
in inertial frame $\mathbf{x}_{\mathrm{m}}$, the velocity in body frame $\mathbf{v}_{\mathrm{bm}}$, the angular velocity $\boldsymbol{\omega}$, and the Euler angles $\varphi, \theta$, and $\psi$

$$
\mathbf{x}=\left[x, y, z, v_{\mathrm{bx}}, v_{\mathrm{by}}, v_{\mathrm{bz}}, p, q, r, \varphi, \theta, \psi\right]^{\mathrm{T}}
$$

The dynamics of these 12 state variables are then given by the kinematic relations (1) and (3), force equation (4), and momentum equation (11). These relations are strongly non-linear, due to the change of coordinates from inertial to body frames and to aerodynamics. The non-linear state-space model has thus the general structure

$$
\left\{\begin{array}{c}
\dot{\mathbf{x}}=\mathbf{f}(\mathbf{x}, \mathbf{u}) \\
\mathbf{y}=\mathbf{h}(\mathbf{x})
\end{array}\right.
$$

where the measurement vector $\mathbf{y}$ is provided by the available sensors and $\mathbf{u}$ the control input vector. Under classical assumptions on control inputs, e.g. small deflection angles of flight control surfaces and linear model of propulsion, this non-linear model can be reduced to a control-affine one

$$
\left\{\begin{array}{c}
\dot{\mathbf{x}}=\mathbf{f}(\mathbf{x})+\mathbf{G}(\mathbf{x}) \mathbf{u} \\
\mathbf{y}=\mathbf{h}(\mathbf{x})
\end{array}\right.
$$

This type of model retains the non-linear global behaviour of the system while benefiting from interesting results in non-linear control theory [161]. If necessary, a further step towards simplification may be done by linearizing (15) around an operating point or a reference trajectory. The corresponding linear model has the form

$$
\left\{\begin{array}{c}
\dot{\mathbf{x}}=\mathbf{A x}+\mathbf{B u} \\
\mathbf{y}=\mathbf{C x}
\end{array}\right.
$$

with A, B, C possibly time-varying.

\subsubsection{Additional features}

The structure of the measurement vector $\mathbf{y}$ depends on the types of sensors embedded on the aircraft. However, the measurement equation for navigation purpose is often linear, which simplifies (14) and (15). Combining sensors from Table 1 may even allow the entire state vector to be observed, which makes more analytical redundancy available. These sensors are obviously subject to noise and inaccuracies that should be dealt with.

Another important characteristic of these statespace models is that their parameters are strongly uncertain, if only because the aerodynamic coefficients are not well known (they are usually obtained through wind tunnel data). Unmodelled disturbances (such as wind turbulence) may also affect dynamics. Hence, and since fault diagnosis aims at comparing the fault-free behaviour specified by the model with the observed one, it is important to avoid linearization whenever possible. Consider, for instance, the decoupled longitudinal and lateral linear models that are sometimes considered for flight control systems. When an actuator fault occurs, strong couplings appear between the axes, which makes this modelling inadequate for robust fault diagnosis.

Although most aerospace systems are closed-loop controlled (Fig. 4), this closed-loop structure is seldom taken into account and the large majority of FDI methods uses only open-loop models. A few strategies have nevertheless been proposed to make explicit use of relevant information concerning faults that is propagated in closed-loop control signals (section 4.6), showing promising results.

\subsection{Faults on sensors and actuators}

Faults may be caused by component aging, battle damage, electromagnetic disturbances or natural phenomena such as severe wind gusts or icing (see references $[\mathbf{1}, \mathbf{2 5}, \mathbf{3 2}, \mathbf{1 2 0}, \mathbf{1 6 2 - 1 6 4}]$ for a history of actual fault cases). Focusing on consequences of such incidents, this section provides a description of typical sensors and actuators in aerospace applications and, most important for simulation, a realistic modelling of typical fault modes that may affect these devices. The chain of actuation and sensing is illustrated for a single-input and single-output system in Fig. 5.

Basically, an actuator fault is modelled as a discrepancy between the computed control input $u_{\mathrm{c}}$ and the one actually achieved by the actuator $u_{\mathrm{a}}$. Similarly, a sensor fault is modelled as a discrepancy between the actual output of the system $y_{\mathrm{a}}$ and the sensor output $y_{\mathrm{s}}$. In practical operation, the only information available for fault diagnosis is the knowledge of $u_{\mathrm{c}}, y_{\mathrm{s}}$ and a model of the system.

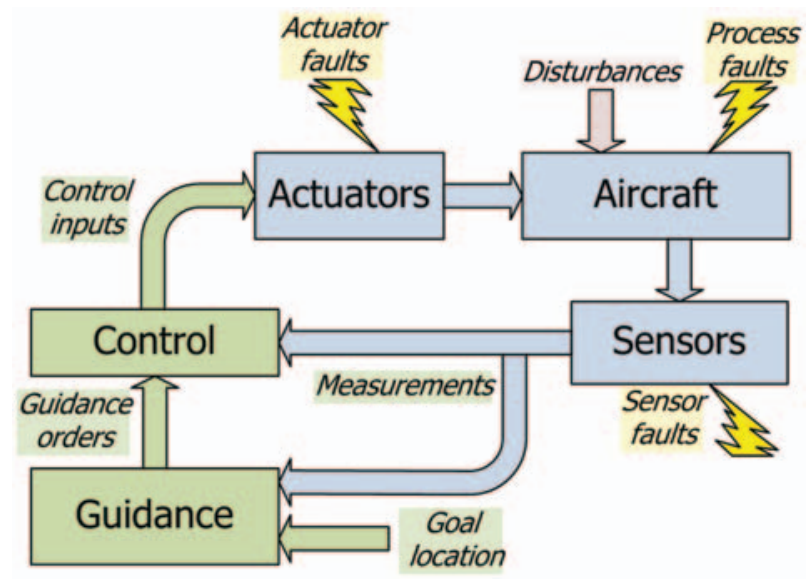

Fig. 4 Closed-loop guidance and control for aircraft 


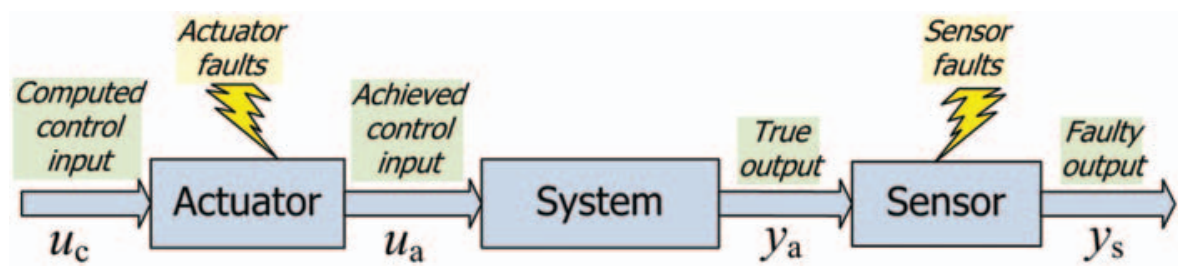

Fig. 5 Chain of actuation and sensing

\subsubsection{Sensors}

The main sensors embedded in aerospace vehicles are inertial measurement units (IMU) comprising accelerometers and gyros that measure non-gravitational acceleration and angular velocity, coupled with inertial navigation systems (INS) that use these measurements to estimate the position and orientation of the vehicle. Measurements from IMU/INS are frequently combined with those of GPS sensors measuring position in inertial frame, to cope with the drift of IMU outputs [165]. Micromechanical technology has allowed huge progress in miniaturization and cost reduction for these devices [166]. Fault detection schemes devoted to IMU/INS/GPS systems can be found in references $[42,45,50,52,64,67]$, mostly based on parity space or observers exploiting analytical redundancy from (1) and (3).

Air data sensing (ADS) systems are used in addition to the previous set of sensors to measure airspeed, dynamic pressure, Mach number, or angles of attack and sideslip [167]. They may include Pitot probes for determining airspeed and surface pressure sensors or mechanical devices for the other air data parameters [140]. Complementary altitude measurement may be provided by barometers or embedded radars.

Very few studies are concerned with a global characterization of sensors in aerospace applications, and even fewer focus on the modelling of sensor faults. In [168], the main technologies used to build sensors for aerospace applications are reviewed, along with their fault modes. Four generic types of faults, common to most sensors, are described: bias (offset), drift (linear or not), scaling (gain, linear, or not), hard fault (loss or locking of signal). They are modelled as follows, where the value of fault parameters $\sigma_{\mathrm{s}}, \varepsilon_{\mathrm{s}}$, and $y_{\mathrm{f}}$ are indicated in Table 2.

$$
y_{\mathrm{s}}=\sigma_{\mathrm{s}}\left(1+\varepsilon_{\mathrm{s}}\right) \cdot y_{\mathrm{a}}+y_{\mathrm{f}}
$$

Severe faults, e.g. loss of measurements, are easy to detect since sensor manufacturers generally provide a built-in test. This is why small anomalies (bias,
Table 2 Model parameters for sensor faults

\begin{tabular}{llllll}
\hline & Bias & Drift & Scaling & Hard fault & No fault \\
\hline$\varepsilon_{\mathrm{s}}$ & 0 & 0 & $\neq 0$ & 0 & 0 \\
$\sigma_{\mathrm{s}}$ & 1 & 1 & 1 & 0 & 1 \\
$y_{\mathrm{f}}$ & $\neq 0$ & $\neq 0$ & 0 & constant & 0 \\
& (constant) & (time-varying) & & & \\
\hline
\end{tabular}

small drift, etc.) should be the focal point of modelbased sensor fault detection.

\subsubsection{Actuators}

Two main groups of actuators are used for the control of an aerial vehicle, namely flight control surfaces and propulsion devices. Flight control surfaces may be according to their location and geometry - elevators, rudders, canards, ailerons, flaps, and spoilers, which are set in motion through hydromechanical or electromechanical circuits. Propulsion devices may be propellers, rotors, jet engines, or thrusters. Note that a jet engine can be seen as a system in itself and dedicated strategies are sometimes employed to diagnose faults in engine components $[\mathbf{6 1}, 98]$. Within the scope of this study, each actuator of an aeronautical system, including jet engines, is considered as a single device, which is monitored through the correct or improper achievement of its desired control input. Four actuator fault modes are distinguished: loss of effectiveness, locking-in-place (jamming, freezing), hard-over, and oscillatory failure $[\mathbf{8 5}, \mathbf{9 0}, \mathbf{1 0 4}, \mathbf{1 1 7}$, 125]. They are modelled as follows

$$
u_{\mathrm{a}}=\sigma_{\mathrm{f}} \cdot k_{\mathrm{f}} \cdot u_{\mathrm{c}}+\left(1-\sigma_{\mathrm{f}}\right) \cdot u_{\mathrm{f}}
$$

where the value of the fault parameters $\sigma_{\mathrm{f}}, k_{\mathrm{f}}$, and $u_{\mathrm{f}}$ after the time of occurrence $t_{\text {fault }}$ are indicated in Table 3.

Parameter faults due to, e.g. icing or wing damage are modelled as changes in the corresponding model parameters (mass, inertia, and aerodynamic coefficients) $[\mathbf{4 0}]$.

\section{METHODS FOR FDI}

Table 4 proposes a classification of FDI approaches according to their aerospace applications, from a collection of more than 100 papers. The rest of this 
Table 3 Model parameters for actuator faults

\begin{tabular}{llllll}
\hline & Loss of effectiveness & Locking-in-place & Hard-over & Oscillatory & No fault \\
\hline$\sigma_{\mathrm{f}}$ & 1 & 0 & 0 & 0 & 1 \\
$k_{\mathrm{f}}$ & $0<k_{\mathrm{f}}<1$ & $\emptyset$ & $\emptyset$ & $\emptyset$ & 1 \\
$u_{\mathrm{f}}$ & 0 & $u_{\mathrm{c}}\left(t_{\text {fault }}\right)$ (constant) & Constant (saturation) & Periodic & 0 \\
\hline
\end{tabular}

Table 4 Types of aerospace models and FDI approaches (acronyms are explained in main text)

\begin{tabular}{|c|c|c|c|c|c|c|c|}
\hline Vehicle / FDI approach & Small aircraft & Rotorcraft & General civil aircraft & Fighter aircraft & Missile & $\begin{array}{l}\text { Rocket/ } \\
\text { reentry vehicle }\end{array}$ & Spacecraft \\
\hline Expert systems & & & {$[74,169]$} & & & & \\
\hline Neural networks & {$[60]$} & {$[62,69]$} & {$[75,82,87]$} & {$[112]$} & {$[\mathbf{1 3 1}]$} & {$[\mathbf{1 3 7}]$} & {$[152]$} \\
\hline SVM & & & {$[92,91]$} & & & & \\
\hline $\begin{array}{l}\text { Principal component } \\
\text { analysis (PCA) }\end{array}$ & & & {$[95,98]$} & {$[115,126]$} & & {$[141]$} & {$[145]$} \\
\hline Parameter estimation & {$[40]$} & & {$[80,81,94,99,102]$} & {$[109]$} & & & {$[149]$} \\
\hline Kalman filters & {$[58,61]$} & {$[68]$} & {$[91,93,105,106]$} & $\begin{array}{l}{[108,110,111} \\
113,118,123]\end{array}$ & & {$[142]$} & {$[144,148,151]$} \\
\hline $\begin{array}{l}\text { Unscented Kalman filter } \\
\text { (UKF)/particle filters }\end{array}$ & {$[45]$} & & {$[\mathbf{1 0 3}]$} & & & & {$[146,147]$} \\
\hline $\begin{array}{l}\text { Set-membership } \\
\text { estimation }\end{array}$ & & {$[67,71]$} & {$[89,101]$} & {$[124]$} & & & \\
\hline Parity space & {$[42,45,49,50,52]$} & & {$[77,97]$} & {$[115,119,128]$} & & {$[140]$} & \\
\hline $\mathrm{UIO}$ & {$[38,44,48,57]$} & {$[66]$} & {$[77]$} & {$[117]$} & & & {$[153]$} \\
\hline System inversion & & {$[65]$} & & {$[114,121,122]$} & {$[135,136]$} & & \\
\hline $\begin{array}{l}\text { Active FDI/ } \\
\text { control-based }\end{array}$ & {$[57,58]$} & & {$[\mathbf{8 0}, \mathbf{8 1}]$} & & {$[134,170]$} & & \\
\hline
\end{tabular}

section is devoted to the description of the operating principles of the main FDI approaches. For the sake of simplicity, the presentation is based on linear models, but pointers to non-linear extensions of the methods considered are provided. In section 4.1, «model-free» methods are described, but throughout sections 4.2 to 4.6 , a dynamical model in state-space form as described in section 3 is assumed to be available.

\subsection{Model-free methods}

When no explicit dynamical model is available, system knowledge boils down to real-time measurements, possibly completed by process history. With such data, two main strategies may be adopted (Fig. 6). The first strategy is classification, which involves building classes from the database either in a supervised way (i.e. with the help of an expert) or in a semisupervised manner (i.e. putting in the same class elements of the database that are deemed close to one another, and relying on an expert only to label the classes). A classifier is then trained with respect to these classes to assign the newly measured variables to classes representative of healthy or faulty behaviours. The second strategy is regression, which builds a statistical model that uses redundancy in the process history to predict the values of variables and generate residuals by comparing predictions to measured values.

\subsubsection{Qualitative approaches}

When no process history is available, the only exploitable information concerning the system monitored is the empirical knowledge of experts, which may be used to build expert systems. They consist of sets of rules that aim to mimic human reasoning, by associating premises and conclusions to determine logical chains of events. A fault is then reported if a forbidden sequence of events is detected. The major drawbacks of this approach are its lack of generality and its inability to handle situations that have not been explicitly taken into account in the design of the knowledge base [171]. Qualitative trend analysis aims at decomposing a measured signal into a sequence of known primitives (e.g. 'stable', 'increasing', and 'decreasing'). This recognition can be achieved either by analysing the sign of successive derivatives of signals and using them in a rule base, or by matching patterns with a database containing samples of known primitives [172]. Both techniques imply the cautious design of heuristic rules. Faults are identified in the same manner as with expert systems.

If a model of the process is available but the confidence in its parameters and quantitative outputs 


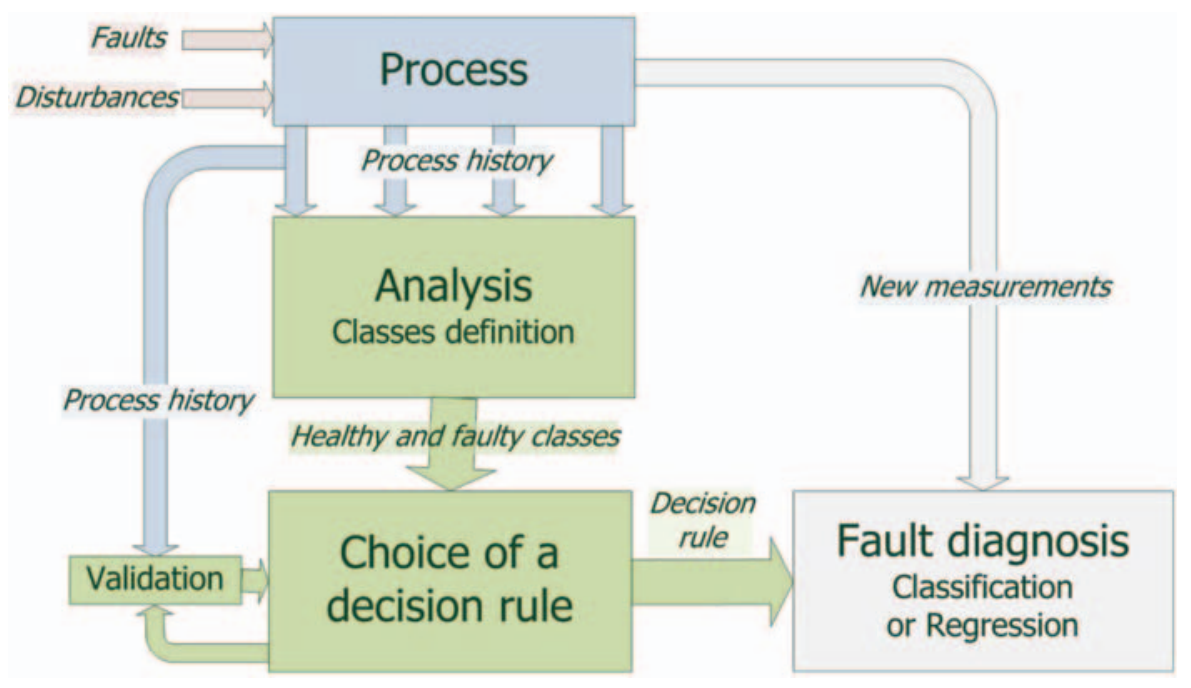

Fig. 6 Principle of model-free approaches

is very low, qualitative equations may be used to express the type of variation of the process variables. This qualitative physics has the same goal as the above-mentioned methods, i.e. to predict the evolution of the process in order to detect abnormal behaviours [173]. Causal links could also be modelled under the form of a signed digraph (SDG) [174]. Qualitative modelling has very limited predictive ability, except in very simple situations, unfortunately.

\subsubsection{Pattern recognition for fault diagnosis}

When some process history is available, diagnosis can be viewed as a pattern recognition task where newly acquired measurements are to be classified in predetermined modes. Prior knowledge takes the form of a database comprising observations of the monitored variables, which may be, e.g. state variables (13) or air data parameters. First, two off-line operations have to be carried out: the data are clustered into classes and a decision rule is trained. Classes are thus defined and each vector of the database is assigned to one of them. For diagnosis, the modes to be considered are the healthy one and all of the possible faulty ones. Labelling may be performed by an expert, if available, or with an algorithm like k-means clustering [175]. If the database contains only non-faulty measurements, another solution is to perform one-class classification [176-178], although this will not make fault isolation practicable. Once the training data have been labelled, a decision rule must be chosen and trained to classify new vectors in the proper classes. Parametric and non-parametric approaches are available for this purpose.

Parametric discrimination aims at computing direct boundaries between classes, using basis functions. The simplest case is linear binary classification, on which most methods are built [179]. Given two classes, its aim is to find a hyperplane that splits the data into two parts with respect to the predefined labels. This separator is designed optimally according to some predefined cost function; a norm should be chosen to evaluate distance to the separator, along with a regularization term to avoid overfitting of the boundary. For non-linear problems where no linear separator exists, more complex functions (quadratic, cubic, etc.) could be used but involve the tuning of a dangerously increasing number of parameters. A very popular solution to design separators for classification has been to resort to neural networks $[112,180]$. Actually, the design difficulty moves from choosing the parameters of the analytical separator to the selection of an activation function and the choice of the structure of the network, i.e. the number of layers and the number of neurons composing each of them. Minimizing the quadratic distance between the output of the network and the label of the appropriate class requires the tuning of the weights of the neurons, usually with the back-propagation algorithm, a local gradient algorithm that may get trapped in suboptimal local solutions. These tools have been widely used in FDI [181-184].

Two key notions are used in modern pattern recognition to build non-linear parametric separators, namely those of kernel and of sparsity. The kernel trick makes it possible to generalize linear methods by mapping the data into some high-dimensional feature space. The output of a kernel machine can be expressed as

$$
\mathbf{y}_{\mathrm{k}}(\zeta)=\sum_{i} \gamma_{i} \cdot \mathbf{k}\left(\zeta, \zeta_{i}\right)
$$


where $\zeta$ is the new input point to classify, $\zeta_{i}$ s the training points, $\mathbf{k}\left(.\right.$, .) the kernel, and $\gamma_{i}$ s the weights to be tuned. This formulation involves an easily computable kernel function, which is used to weigh the contribution of the training points based on the distance between the training and new inputs. Sparsity is also needed, as it would be computationally expensive to have significant weights on all the samples while all are not relevant. This is accomplished through an appropriate design of the cost function to be minimized to find the weights $\gamma_{i}$ of the kernel machine $[\mathbf{1 8 5}, \mathbf{1 8 6}]$. Vapnik's support vector machines (SVM) have popularized these concepts [187]. The goal of an SVM is to find a linear separator of the data in the higher dimensional feature space. This separator is designed in order to achieve structural risk minimization (SRM). It aims at avoiding overfitting, which is the main danger with parametric discrimination approaches such as neural networks. Another advantage of the SVM approach is that weight optimization is a convex problem, thus avoiding the occurrence of local minimizers that plague neural-network tuning. The final function is expressed as a projection onto support vectors. Another interesting approach uses Gaussian processes (GP), which generalize multivariate Gaussian distributions to infinite-dimensional spaces. GP regression has been called Kriging by the geostatistical community [188]. An appropriate choice of the GP covariance, which plays the role of the kernel, makes it possible to reduce computational complexity for largescale problems. Applications of kernel machines to FDI have been reported [176, 177, 189-191] but very few in aerospace $[\mathbf{9 1}, \mathbf{9 2}]$, though it seems a promising way to perform or enhance fault detection. Moreover, the criteria used could be modified to perform regression. It would then become possible to use the same formalism to create a black-box model that can generate residuals by comparing its outputs and the measurements on the system to detect the faults. Finally, it should be pointed out that the choice of the kernel and cost function is crucial and far from trivial, and that adequacy to the data must be carefully checked [188].

If the design of a separator remains intractable, a distance combined with a voting scheme can achieve non-parametric classification. Given the labelled data, a new point is classified in conformity with its neighbourhood. The best-known method is the $k$-nearest neighbour algorithm, which gives its value to the new point according to the majority of the labels of the $k$-nearest points. Of course, a distance should be chosen to determine which points are the 'nearest'. A histogram or a grid could also replace the distance to analyse the neighbourhood influence on the point considered [192, 193].

\subsubsection{Principal component analysis}

PCA achieves dimension reduction by projecting the training data onto the $l$ eigenvectors of the covariance matrix associated to the eigenvalues that are larger than some threshold. Consider that $n_{\mathrm{m}}$ measurements of $n_{\mathrm{v}}$ variables have been acquired in faultfree condition, forming the data matrix $\mathbf{X} \in \mathbb{R}_{v}^{n_{m} \times n}$, assumed to be normalized to zero mean and unit variance [194]. Its covariance matrix is estimated by

$$
\mathbf{S}=\frac{1}{n_{\mathrm{m}}-1} \mathbf{X}^{\mathrm{T}} \mathbf{X}
$$

which can be factorized into

$$
\mathbf{S}=\left[\begin{array}{ll}
\mathbf{T} & \widetilde{\mathbf{T}}
\end{array}\right]\left[\begin{array}{cc}
\Lambda & 0 \\
0 & \widetilde{\Lambda}
\end{array}\right]\left[\begin{array}{ll}
\mathbf{T} & \widetilde{\mathbf{T}}
\end{array}\right]^{\mathrm{T}}
$$

where $\mathbf{T}$ is an $n_{\mathrm{m}} \times l$ matrix and $\boldsymbol{\Lambda}$ an $l \times l$ diagonal matrix of eigenvalues, with $l$ the chosen number of principal components. The projection of a newly measured vector $\zeta$ into the principal subspace is given by

$$
\widehat{\zeta}=\mathbf{T T}^{\mathrm{T}} \zeta
$$

and into the residual subspace by

$$
\widetilde{\zeta}=\widetilde{\mathbf{T}} \widetilde{\mathbf{T}}^{\mathrm{T}} \zeta
$$

A norm of $\widetilde{\zeta}$ can thus be used as a residual indicative of the presence of faults, as it should remain small in fault-free condition. Moreover, the magnitude of a fault on a single variable may be estimated by computing the difference between the measurement of this variable and its reconstruction using the projection matrix and the measurements of all the other variables [195]. Robustification to outliers via a modified computation of the covariance matrix has been proposed in reference [196].

This framework assumes linear relations between measured variables, which is not always valid. It can be extended to the non-linear case through the kernel trick [197], or other types of decompositions such as Independent Component Analysis [198]. A recursive form also exists to deal with dynamical systems [199]. A Partial-Least-Squares (PLS) approach [200] can be viewed as closely related.

\subsection{Parameter estimation}

The mappings $\mathbf{f}(\cdot)$ and $\mathbf{h}(\cdot)$ of the non-linear statespace model (14) depend on a set of physical parameters $\mathbf{p}_{\phi}$, comprising mass, inertia, geometrical characteristics and functions converting actuator actions 
into force and momentum (e.g. aerodynamic coefficients). These parameters are not generally measured and may depend on time. Moreover, state equations may not be straightforward functions of $\mathbf{p}_{\phi}$, but may depend instead of a vector of behavioural parameters $\underline{\theta}$, which may have no physical meaning. Identification techniques should be considered to detect process faults that may affect the values of these parameters, provided that they are identifiable [201]. One of many possible courses of action is to distinguish the following five steps $[\mathbf{1 5}, \mathbf{1 7}, \mathbf{2 0 2 - 2 0 5}]$.

1. From model (14), establish input-output relations

$$
\mathbf{y}_{\mathrm{p}}=\mathbf{h}_{\mathrm{p}}\left(\mathbf{u}_{\mathrm{p}}, \underline{\boldsymbol{\theta}}\right)
$$

where $\mathbf{y}_{\mathbf{p}}$ may include successive time derivatives of the measured output $\mathbf{y}$, and $\mathbf{u}_{\mathrm{p}}$ successive values of the control inputs on a time horizon.

2. Determine the relationship between the model parameters $\boldsymbol{\theta}$ and the physical constants $\mathbf{p}_{\phi}$

$$
\underline{\boldsymbol{\theta}}=\mathbf{g}_{\mathrm{p}}\left(\mathbf{p}_{\phi}\right)
$$

3. Compute an estimate $\widehat{\widehat{\boldsymbol{\theta}}}$ of model parameters from equation (4.6), with on-line measurements.

4. Compute an estimate of the physical parameters, $\widehat{\mathbf{p}}_{\phi}=\mathbf{g}_{\mathrm{p}}^{-1}(\widehat{\widehat{\theta}})$.

5. Generate residuals by comparing $\widehat{\mathbf{p}}_{\phi}$ to known nominal or acceptable values of these parameters. If nominal values are unknown or uncertain, residuals may still be generated by computing the difference between the current estimate $\widehat{\mathbf{p}}_{\phi}(t)$ and a past value $\widehat{\mathbf{p}}_{\phi}\left(t-t_{\mathrm{h}}\right)$, where $t_{\mathrm{h}}$ is a predetermined time horizon.

Parameter estimation methods to address Step 3 can be found in references $[9,206]$. A possible way to simplify (24) is to linearize the non-linear dynamics (14) and then to aggregate successive time derivatives to obtain a model that is linear in the parameter vector $\theta$

$$
\mathbf{y}_{\mathrm{p}}=\mathbf{H}_{\mathrm{p}}\left(\mathbf{u}_{\mathrm{p}}\right) \cdot \underline{\boldsymbol{\theta}}
$$

Estimation of $\widehat{\underline{\boldsymbol{\theta}}}$ can then be achieved on-line through, e.g. recursive least squares [7]. Note that an important problem that may arise is the on-line determination of successive time derivatives of noisy measured outputs y. In the general non-linear case, non-linear optimization methods should be called upon, even if the techniques involved may be computationally much more expensive and not guaranteed to converge to an optimal solution [10]. Guaranteed global optimization methods such as made possible by interval analysis may be considered, but their use is only possible on limited types of problems [207]. Surrogate-based optimization may be an interesting alternative to reduce computational cost $[\mathbf{2 0 8}, \mathbf{2 0 9}]$. Other types of approaches, such as subspace identification $[210,211]$, are also to be considered.

At Step 5, a set of admissible values could be considered instead of a single nominal value $[\mathbf{2 1 2}, 213]$. In this context, a set of possible estimates of the parameters may be determined (approximated by, e.g. vector intervals, ellipsoids, or zonotopes), and diagnosis can then be achieved by checking whether the intersection between this estimated set and the set of admissible values is void, which suggests the presence of a fault [214-216].

\subsection{State estimation}

Estimating the state of the system makes it possible to create residuals by comparing the reconstructed signals with their measured or expected values $[217,218]$. State estimators may be classified according to how uncertainty is taken into account.

\subsubsection{Deterministic approach}

Luenberger observers [219] allow the reconstruction of the state variables under deterministic hypotheses. Observer-based FDI methods are now classical and have been widely used for a large panel of applications [220-222]. Consider the nominal deterministic linear state-space model (16) first

$$
\left\{\begin{array}{c}
\dot{\mathbf{x}}=\mathbf{A x}+\mathbf{B u} \\
\mathbf{y}=\mathbf{C x}
\end{array}\right.
$$

and the corresponding full-state observer

$$
\left\{\begin{array}{c}
\dot{\hat{\mathbf{x}}}=\mathbf{A} \hat{\mathbf{x}}+\mathbf{B u}+\mathbf{L}(\mathbf{y}-\mathbf{C} \hat{\mathbf{x}}) \\
\hat{\mathbf{y}}=\mathbf{C} \hat{\mathbf{x}}
\end{array}\right.
$$

The state-estimation error $\mathbf{e}_{\mathrm{x}}=\mathbf{x}-\hat{\mathbf{x}}$ satisfies

$$
\dot{\mathbf{e}}_{\mathrm{x}}=(\mathbf{A}-\mathbf{L C}) \mathbf{e}_{\mathrm{x}}
$$

and $\mathbf{e}_{\mathrm{x}}$ asymptotically goes to zero if the model is correct and $\mathbf{L}$ is chosen in such a way that $(\mathbf{A}-\mathbf{L C})$ is Hurwitz, which is always possible if the pair $(\mathbf{C}, \mathbf{A})$ is observable. Consider now a time-varying fault vector $\mathbf{w}_{\mathrm{f}}$ affecting the state as

$$
\left\{\begin{array}{c}
\dot{\mathbf{x}}=\mathbf{A x}+\mathbf{B u}+\mathbf{E}_{\mathrm{f}} \mathbf{w}_{\mathrm{f}} \\
\mathbf{y}=\mathbf{C x}
\end{array}\right.
$$

This model encompasses actuator, sensor and even structural faults, as $\mathbf{w}_{\mathrm{f}}$ can take any value. Equation (29) becomes

$$
\dot{\mathbf{e}}_{\mathbf{x}}=(\mathbf{A}-\mathbf{L C}) \mathbf{e}_{\mathbf{x}}+\mathbf{E}_{\mathrm{f}} \mathbf{w}_{\mathrm{f}}
$$


The estimation error is thus sensitive to faults, and the output estimation error $\mathbf{e}_{\mathrm{y}}=\mathbf{y}-\hat{\mathbf{y}}$ can be used as a residual. In the frequency domain, and if the effect of initial conditions can be neglected, one can write $\overline{\mathbf{e}}_{\mathrm{y}}(s)=\mathbf{C}(s \mathbf{1}-\mathbf{A}+\mathbf{L C})^{-1} \mathbf{E}_{\mathrm{f}} \overline{\mathbf{w}}_{\mathrm{f}}(s)$. If the Laplace transform $\overline{\mathbf{w}}_{\mathrm{f}}(s)$ of $\mathbf{w}_{\mathrm{f}}$ does not belong to the kernel of $\mathbf{C}(s \mathbf{1}-\mathbf{A}+\mathbf{L C})^{-1} \mathbf{E}_{\mathrm{f}}$, then the residual is sensitive to $\mathbf{w}_{\mathrm{f}}$. Note that observers for fault diagnosis need not be full-state, since only output reconstruction may be required, which suggests that reduced-order observers may be sufficient.

Such an observer, driven by all inputs and outputs of the system, is sometimes referred to as the simplified observer scheme [73]. Even if it may detect faults, this scheme generally does not allow fault isolation since all output estimates may react to any fault affecting the process. Two types of banks of observers have been designed for generating residuals that are sensitive to desired sets of faults, namely the dedicated observer scheme (DOS) and the generalized observer scheme (GOS) [73]. A DOS is a bank of observers driven by only one sensor output (or control input) and thus sensitive to only one sensor fault (or one actuator fault). In a GOS, observers are driven by all outputs (or inputs) but one and thus sensitive to all faults except one. Figure 7 illustrates the structure of DOS and GOS for sensor FDI.

Non-Linear state estimation is often addressed by linearizing the model around an operating point or along a trajectory, in order to apply the previous techniques. This has given birth to the extended Luenberger observer (ELO) [223, 224]. Since linearizing implies losing information, the use of fully non-linear observers have been investigated for fault diagnosis [221]. However, no general non-linear structure can be defined and tuning remains complex. Available results mainly concern adaptive observers [225-229] and high-gain observers [230-232]. Recently, a new form of non-linear observers has been proposed [233, 234], which is designed via the solving of a partial differential equation. Its applicability to observer-based fault diagnosis remains to be evaluated. Sliding mode observers are also an interesting alternative, since they allow the direct estimation of faults that have broken the sliding motion [235-237].

To avoid heavy computations, multiple-model strategies are also being investigated. They assume that the non-linear model of the system can be approximated by interpolating between local linear models. This Takagi-Sugeno representation may be obtained analytically or by system identification [238]. It is then possible to build a set of interpolating linear observers to achieve diagnosis [239, 240].

\subsubsection{Stochastic approach}

Kalman filtering [241] achieves state estimation in a stochastic context where the existence of state perturbations and measurement noise is explicitly taken into account by assuming that they have known Gaussian probability distributions (or that the first and second moments of their probability distributions are known). In steady-state and fault-free condition, the innovation of a Kalman filter should be white noise with zero mean and known covariance. It can thus be monitored by statistical tests on mean or variance to diagnose faults. This was initially introduced in reference [242] and has been widely exploited since then [243-245]. Banks of filters can also be defined, the two principal architectures being multiple model adaptive estimation (MMAE) and interacting multiple model (IMM).

MMAE [108, 246] is a collection of filters using hypothesized models of fault-free and faulty behaviours, designed in DOS or GOS and running independently. The stochastic nature of the innovations of the filters makes it possible to compute a probability for each model, and thus to provide a confidence level for fault isolation. IMM [123, 247-249] also

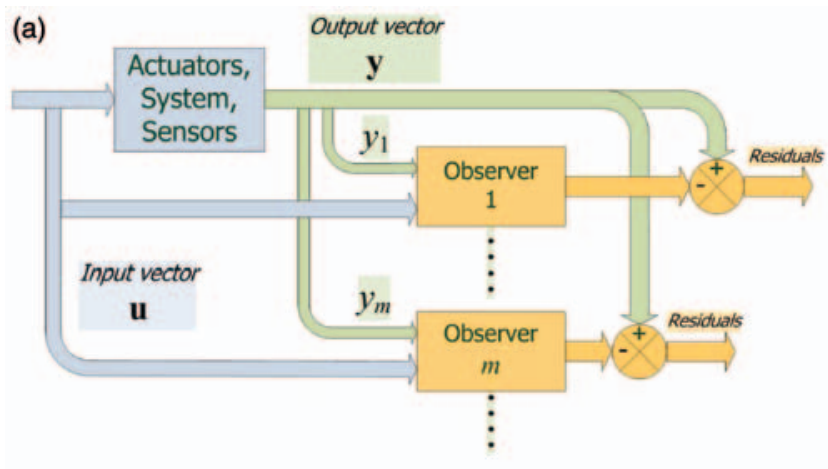

Dedicated Observer Scheme (DOS)

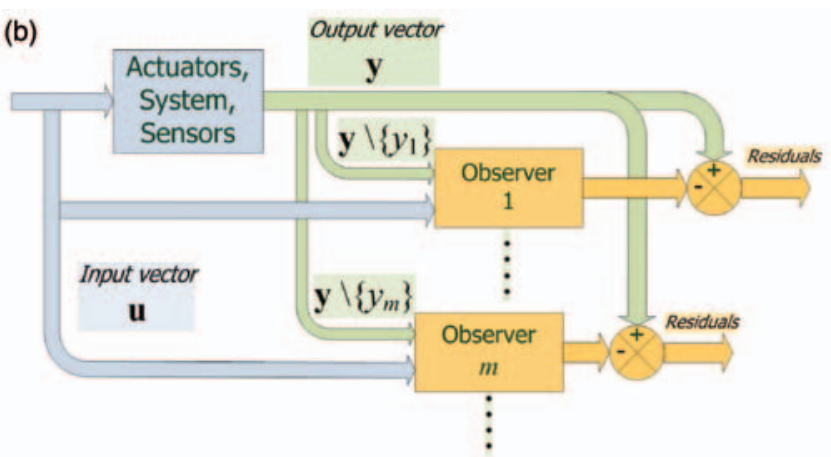

Generalized Observer Scheme (GOS)

Fig. 7 Banks of observers for detection and isolation of sensor faults 
integrates the probability of switching from one model to another as a Markov chain and achieves a fusion of the estimates.

Extension to non-linear systems is commonly addressed through linearization around the current mean estimate within the extended Kalman filter (EKF) $[\mathbf{2 5 0}]$. Contrary to the EKF, the unscented Kalman filter (UKF) does not linearize the model [251] and predicts the system behaviour using evaluations of the non-linear model at a set of points roughly approximating a Gaussian distribution of the state vector $[\mathbf{2 5 2}, \mathbf{2 5 3}]$. Based on a similar idea, sequential Monte Carlo methods such as particle filtering $(\mathrm{PF})$ are a very promising approach to deal with non-linearity and non-Gaussian distributions $[\mathbf{1 4 6}, 254]$. PF is now used for tackling complex fault detection issues [255-257].
In order to decouple the unknown state variables and generate residuals that are only sensitive to faults, the parity vector $\mathbf{W y}$ is computed. $\mathbf{W}$ is a projection matrix that should be orthogonal to $\mathbf{C}$ to ensure $\mathbf{W C}=\mathbf{0}$, and such that $\mathbf{W} \mathbf{E}_{\mathbf{f}} \neq \mathbf{0}$, to allow faults to be detected. This strategy is useful to manage hardware redundancy efficiently, i.e. when multiple sensors measure the same variables [265] or with pyramidal IMU configurations [154].

Extension to dynamic systems exploits model structure and temporal redundancy on a time horizon $t_{\mathrm{h}}$. Consider the discrete-time version of the faultfree model (16) with A, B, C assumed constant

$$
\left\{\begin{array}{c}
\mathbf{x}(k+1)=\mathbf{A x}(k)+\mathbf{B u}(k) \\
\mathbf{y}(k)=\mathbf{C x}(k)
\end{array}\right.
$$

Successive measurements on the time horizon $[k$; $\left.k+t_{\mathrm{h}}\right]$ satisfy

$$
\begin{gathered}
\mathbf{y}(k)=\mathbf{C x}(k) \\
\mathbf{y}(k+1)=\mathbf{C} \mathbf{x}(k+1)=\mathbf{C A x}(k)+\mathbf{C B u}(k) \\
\vdots \\
\mathbf{y}\left(k+t_{\mathrm{h}}\right)=\mathbf{C A}^{t_{\mathrm{h}}} \mathbf{x}(k)+\mathbf{C A}^{t_{\mathrm{h}}-1} \mathbf{B u}(k)+\ldots+\mathbf{C B u}\left(k+t_{\mathrm{h}}-1\right)
\end{gathered}
$$

\subsubsection{Bounded-error approach}

The methods presented so far either do not use any explicit uncertainty representation or assume a probability distribution for the uncertain variables, most often Gaussian. An alternative approach is to use bounds on acceptable errors. This bounded-error approach can be used for linear and non-linear models. In non-linear state estimation, for example, interval analysis can be used to predict the evolution of the set of possible values for the state vector [207, 258]. Part of the predicted set that are inconsistent with measurements may then be eliminated. Fault detection can thus be performed by checking whether the resulting set is empty $[\mathbf{2 1 2}, \mathbf{2 5 9}]$.

\subsection{Parity space}

Parity relations eliminate unknown state variables from static or dynamic model equations to produce residuals that only depend on the system inputs and outputs $[14,260,261]$. Links between parity space methods and observers have been investigated in references [262-264].

Consider first the (static) measurement equation with faults

$$
\mathbf{y}=\mathbf{C x}+\mathbf{E}_{\mathrm{f}} \mathbf{w}_{\mathrm{f}}
$$

This can be written as

$$
\mathbf{Y}\left(k, t_{\mathrm{h}}\right)=\mathbf{H}\left(t_{\mathrm{h}}\right) \mathbf{x}(k)+\mathbf{G}\left(t_{\mathrm{h}}\right) \mathbf{U}\left(k, t_{\mathrm{h}}\right)
$$

where

$$
\begin{gathered}
\mathbf{Y}\left(k, t_{\mathrm{h}}\right)=\left[\begin{array}{c}
\mathbf{y}(k) \\
\mathbf{y}(k+1) \\
\vdots \\
\mathbf{y}\left(k+t_{\mathrm{h}}\right)
\end{array}\right], \mathbf{U}\left(k, t_{\mathrm{h}}\right)=\left[\begin{array}{c}
\mathbf{u}(k) \\
\mathbf{u}(k+1) \\
\vdots \\
\mathbf{u}\left(k+t_{\mathrm{h}}\right)
\end{array}\right] \\
\mathbf{H}\left(t_{\mathrm{h}}\right)=\left[\begin{array}{c}
\mathbf{C} \\
\mathbf{C A} \\
\vdots \\
\mathbf{C A}^{\mathrm{t}_{\mathrm{h}}}
\end{array}\right], \mathbf{G}\left(t_{\mathrm{h}}\right)=\left[\begin{array}{cccc}
0 & 0 & \cdots & 0 \\
\mathbf{C B} & 0 & \cdots & 0 \\
\vdots & \ddots & \ddots & \vdots \\
\mathbf{C A}^{t_{\mathrm{h}}-1} \mathbf{B} & \cdots & \mathbf{C B} & 0
\end{array}\right]
\end{gathered}
$$

This new system is static, and a projection matrix $\mathbf{W}$ can be seeked for such that $\mathbf{W H}\left(t_{\mathrm{h}}\right)=\mathbf{0}$. The continuous-time formulation is very similar, except that successive time derivatives of inputs and outputs are involved instead of successive values in time [266].

Extension to some classes of non-linear systems has been investigated. The design of analytical redundancy relations when the non-linear mappings from model (14) are polynomial in the state and input variables is addressed in references $[\mathbf{2 6 7}, \mathbf{2 6 8}]$ with the help of elimination theory. An extension to 
state-affine systems is presented in reference [269] and to input-affine systems in reference [270], both based on the geometrical concepts described in section 4.5.4.

\subsection{Decoupling strategies}

Important issues in fault diagnosis are robustness to exogenous inputs such as state disturbances and the design of filters that are sensitive to some faults and as decoupled as possible from other. Consider a vector of state disturbances $\mathbf{w}_{\mathrm{d}}$ that affect the system (30) as

$$
\left\{\begin{array}{c}
\dot{\mathbf{x}}=\mathbf{A x}+\mathbf{B u}+\mathbf{E}_{\mathrm{d}} \mathbf{w}_{\mathrm{d}}+\mathbf{E}_{\mathrm{f}} \mathbf{w}_{\mathrm{f}} \\
\mathbf{y}=\mathbf{C x}
\end{array}\right.
$$

The methods considered so far are not able to distinguish the undesired unknown input $\mathbf{w}_{\mathrm{d}}$ from the input $\mathbf{w}_{\mathrm{f}}$ resulting from faults. For example, the fullstate observer-based residual (31) now becomes

$$
\mathbf{e}_{\mathbf{x}}=(\mathbf{A}-\mathbf{L C}) \mathbf{e}_{\mathbf{x}}+\mathbf{E}_{\mathrm{f}} \mathbf{w}_{\mathrm{f}}+\mathbf{E}_{\mathrm{d}} \mathbf{w}_{\mathrm{d}}
$$

Ideally, a decoupling observer-based filter

$$
\left\{\begin{array}{l}
\dot{\widehat{\mathbf{x}}}=\widehat{\mathbf{f}}(\widehat{\mathbf{x}}, \mathbf{u}, \mathbf{y}) \\
\mathbf{r}=\widehat{\mathbf{h}}(\widehat{\mathbf{x}}, \mathbf{u}, \mathbf{y})
\end{array}\right.
$$

should generate residuals $\mathbf{r}$ sensitive to $\mathbf{w}_{\mathrm{f}}$, insensitive to $\mathbf{w}_{\mathrm{d}}$ and converging to zero when there is no fault [271]. A necessary condition for such an exact decoupling to be possible is that $\operatorname{dim} \mathbf{w}_{\mathrm{d}}<\operatorname{dim} \mathbf{y}$. Four approaches addressing this problem are described in this section. Eigenstructure assignment (section 4.5.1) and unknown-input observers (UIO) (section 4.5.2) are closely related, since they both seek for exact decoupling via linear algebra. NonLinear geometric approaches (section 4.5.4) generalize these ideas to non-linear systems with the help of differential geometry, while norm-based approaches (section 4.5.3) use robust control theory for approximate decoupling.

\subsubsection{Eigenstructure assignment}

In eigenstructure assignment [262], the vector of residuals is computed by left multiplying the output-estimation error $\mathbf{e}_{\mathrm{y}}$ of the full-state observer (28) by some weighting matrix $\mathbf{W}$ as

$$
\mathbf{r}=\mathbf{W e} \mathbf{e}_{\mathrm{y}}=\mathbf{W C}(\mathbf{x}-\widehat{\mathbf{x}})
$$

The coupled design of $\mathbf{W}$ and the observer gain $\mathbf{L}$ is then undertaken to nullify the transfer from $\mathbf{w}_{\mathrm{d}}$ to $\mathbf{r}$, which implies that $\mathbf{W} \mathbf{C E}_{\mathrm{d}}=\mathbf{0}$, as well as to ensure the convergence of the observer [272]. Note that parity space residuals could also be made insensitive to unknown inputs with similar design principles [273].

\subsubsection{Unknown-input observer}

A very useful extension of observers for fault detection is the UIO, which can be designed in deterministic or stochastic settings. The UIO aims at performing state estimation with minimal influence of the unknown inputs (i.e. exogenous disturbances) [38, 274-277]. The structure of a linear UIO for residual generation is given by

$$
\left\{\begin{array}{c}
\dot{\widehat{\mathbf{x}}}=\mathbf{F} \widehat{\mathbf{x}}+\mathbf{T B u}+\left(\mathbf{K}_{1}+\mathbf{K}_{2}\right) \mathbf{y} \\
\mathbf{r}=(\mathbf{1}-\mathbf{C H}) \mathbf{y}-\mathbf{C} \widehat{\mathbf{x}}
\end{array}\right.
$$

where, to ensure decoupling and asymptotic convergence, the design matrices $\mathbf{F}, \mathbf{T}, \mathbf{K}_{1}, \mathbf{K}_{2}, \mathbf{H}$ should be chosen such that

$$
\left\{\begin{array}{c}
(\mathbf{H C}-\mathbf{1}) \mathbf{E}_{\mathbf{d}}=\mathbf{0} \\
\mathbf{T}=\mathbf{1}-\mathbf{H C} \\
\mathbf{F}=\mathbf{A}-\mathbf{H C A}-\mathbf{K}_{\mathbf{1}} \mathbf{C} \text { is Hurwitz } \\
\mathbf{K}_{2}=\mathbf{F H}
\end{array}\right.
$$

If such a design exists, observers that are sensitive to all faults but one and insensitive to disturbances can be incorporated in a GOS architecture, or in a dual fashion in a DOS architecture.

The extended unknown input observer (EUIO) [11] deals with non-linearities via linearization around current trajectory, like an EKF. Fully non-linear extensions of the UIO have been considered for systems with Lipschitz non-linearities in reference [277-279], and for systems that can be transformed into such systems [280]. An algebraic approach has also been proposed [281, 282].

\subsection{3 $\mathcal{H}_{\infty}$ strategies}

If exact decoupling of unknown inputs from faults is not achievable, it may be considered in the worstcase sense. Norm-based methods [12, 283-285] aim at maximizing the effect of faults on residuals according to the $\mathcal{H}_{\infty}$ norm (maximum induced gain of the transfer matrix from faults to residuals), while minimizing a measure of the influence of disturbances (minimum induced gain of the transfer matrix from disturbances to residuals). If the initial problem can be put into standard form, filter design is then generally tackled by linear matrix inequalities (LMI) [286]. Estimation of faults in this context has also been investigated [287].

\subsubsection{Non-Linear geometric approaches}

Differential-geometric tools are used in reference [288] to check whether it is possible to generate 
diagnosis filters that are sensitive to one fault only and decoupled from other faults and disturbances. This problem is solvable if there exists observable subsystems that are unaffected by all faults but one. This non-linear geometric formulation is closely related to parity space and UIO approaches, since it still exploits the null-space of the observability distribution to generate residuals [289]. Differentialalgebraic approaches have also been proposed in reference [290, 291].

Inversion-based FDI reconstructs control inputs to diagnose faults $[\mathbf{2 9 2}, \mathbf{2 9 3}]$. The left-inverse of the non-linear system [294] is computed to obtain a new dynamical model that reconstructs faults from original inputs, outputs, and their successive derivatives. Considering the problem from the input side is an interesting and relevant change of viewpoint, since most fault diagnosis methods generate residuals by comparing estimated outputs with their measured values. In this context, the fact that most aerospace vehicles are equipped with an IMU (Table 1) makes it possible to use the force equation as a static relation to reconstruct control inputs that have been achieved by actuators $[\mathbf{1 3 5}, \mathbf{1 3 6}]$. Residuals can then be generated by comparing these reconstructed inputs with the values that have been sent by the control algorithm to the system, without the need to integrate a dynamical model.

\subsection{Control-related strategies}

All the methods presented in the previous sections are open-loop, in the sense that feedback control is not taken into account in filter design. This seems unfortunate, as control information may provide additional insight on the system behaviour and thus help detect and isolate faults.

An interesting idea in this context is active fault diagnosis, where an auxiliary input may be injected into the system to enhance fault identification [295-297]. This technique has been recently applied to small UAVs $[\mathbf{5 7}, \mathbf{5 8}]$, with the addition of a small sinusoidal component to the control signal of actuators suspected of faults. This strategy is appealing, even if the design of such signals should be cautious since the additional input may seriously deteriorate performance in normal operating condition or even destabilize the system [298].

As there is a trade-off to achieve between fault detection and performance of the closed-loop system, designing simultaneously control laws and observation filters has been addressed [299, 300]. Multi-objective optimization methods are used to maximize the effect of faults on the diagnosis filter while still achieving control objectives [285].
The effect of feedback on fault diagnosis methods has been analysed in reference [301] and more recently in reference [302], where model uncertainty or multiplicative faults are shown to make the residuals depend on the control signal. More generally, the control input holds relevant information concerning faults in a feedback-controlled system. Following this idea, it has been pointed out in reference $[\mathbf{1 3 4}, \mathbf{1 7 0}]$ that control objectives can be used as residuals indicating the presence of faults and even allow fault isolation.

\section{RESIDUAL EVALUATION}

After residuals - presumably noisy and disturbed have been generated by methods from section 4 , there is the need to analyse them on-line to provide Boolean decisions on whether they significantly differ from those that would be generated during normal operation. Given this collection of Boolean values, the fault-incidence matrix should be built, to express the influence of each fault on residuals [303, 304]. To achieve isolation, each fault should affect a different set of residuals - this is, e.g. what is seeked for by DOS and GOS architectures.

The problem of residual analysis boils down to comparing the characteristics of each signal with what is expected. This usually concerns a change in the mean, which should be statistically close to zero in normal operation; a change in the variance or another statistical property could also be monitored $[5,7]$, but will not be considered in what follows. The evaluation methods presented in this section are independent from the residual generation step. However, it should be noted that the tuning of these tests should be coordinated with that of the residual generation method employed to obtain adequate robustness.

To present the main thresholding methods, a scalar residual $r(t)$ is considered. The residual-evaluation methods provide a scalar binary decision function, which should return false if the mean $\bar{r}$ of the residual is close enough to its initial mean (usually zero) and true if a jump or a drift in the signal has been detected. This could be formulated as a test between two hypothesis at each time step, $\mathcal{H}_{0}$ corresponding to false and $\mathcal{H}_{1}$ to true [305]

$$
\begin{cases}\mathcal{H}_{0}: & \bar{r}(t)=\mu_{0}, \quad \mu_{0} \operatorname{known}\left(\mu_{0}=0\right) \\ \mathcal{H}_{1}: & \bar{r}(t)=\mu_{1}, \quad \mu_{1} \text { known or unknown }\end{cases}
$$

Most statistical tests assume a Gaussian distribution for $r$ and require the knowledge of its nominal mean $\mu_{0}$ and variance $\sigma_{0}^{2}$. These values can be estimated on the first data obtained in operation, provided that the 
system can be assumed to be non-faulty at the beginning. The size of the change to be detected $\mu_{1}$ may be fixed or estimated on-line. Four decision situations may arise, depending on the correspondence between the true hypothesis and the one chosen by the test, as summarized by Table 5 . The contradictory objectives of minimizing non detection and false alarm are then a major concern when choosing and tuning a threshold or a statistical test.

Note that $r$ is not necessarily Gaussian, especially when dealing with non-linear models. To allow the statistical tests described hereinafter to remain applicable, the asymptotic local approach [306, 307] defines the modified residual on $N$ observations as

$$
r_{\text {loc }}=\frac{1}{\sqrt{N}} \sum_{t=1}^{N} r(t)
$$

Despite the absence of knowledge of the statistical properties of $r, r_{\text {loc }}$ is approximately Gaussian for a sufficiently large $N$, and thus eligible to a hypothesis test similar to (44).

\subsection{Static thresholding}

Without any statistical consideration, the «threesigma» rule chooses bilateral fixed thresholds equal to $\mu_{0} \pm v \sigma_{0}$, where $v \geq 3$ usually [308], relying on the fact that 99.7 per cent of the points of a Gaussian distribution lie within three standard deviations of its mean. The decision is $\mathcal{H}_{1}$ when the value of the residual falls outside the thresholds, else the decision is $\mathcal{H}_{0}$. This simple test can be used to detect large jumps in residuals, but is likely to miss detection when the size of the change is of the same order of magnitude as the standard deviation of the process.

A robust version of static thresholding assumes that bounds on model uncertainties, disturbances and noise are known and propagates them through the residual generator to provide bilateral thresholds in the worst-case sense (thus conservative) $[\mathbf{3 0 9}, 310]$.

\subsection{Student's $t$-test}

This test checks whether the signal follows a Gaussian distribution $\left(\mu_{0}, \sigma_{0}\right)$, which leads to an automatic thresholding provided by Student's table given a required confidence level (e.g. 95 per cent) [311]. If this threshold is crossed, then the decision is $\mathcal{H}_{1}$.

Table 5 Decision situations in a two-hypothesis test

\begin{tabular}{lll}
\hline & Decide $\mathcal{H}_{0}$ & Decide $\mathcal{H}_{1}$ \\
\hline $\mathcal{H}_{0}$ true $($ no fault $)$ & Proper decision & False alarm \\
$\mathcal{H}_{1}$ true $($ fault $)$ & Non-detection & Proper decision \\
\hline
\end{tabular}

\subsection{Generalized likelihood ratio test}

This test is based on the likelihood ratio $\Lambda(r)$ of the probability that the mean of $r$ is $\mu_{1} \neq \mu_{0}$ to the probability that it is $\mu_{0}$, still assuming that the signal is Gaussian with standard deviation $\sigma_{0}$ [5]. On $N$ successive independent observations of $r(t)$, the likelihood ratio is

$$
\begin{aligned}
\Lambda(r) & =\frac{P\left(r \mid \mathcal{H}_{1}\right)}{P\left(r \mid \mathcal{H}_{0}\right)}=\frac{\exp \left(-\frac{\sum_{t=1}^{N}\left(r(t)-\mu_{1}\right)^{2}}{2 \sigma_{0}^{2}}\right)}{\exp \left(-\frac{\sum_{t=1}^{N}\left(r(t)-\mu_{0}\right)^{2}}{2 \sigma_{0}^{2}}\right)} \\
& =\exp \left[\frac{\left(\mu_{1}-\mu_{0}\right)}{\sigma_{0}^{2}} \sum_{t=1}^{N}\left(r(t)-\frac{\mu_{0}+\mu_{1}}{2}\right)\right]
\end{aligned}
$$

The likelihood-ratio test, built on the NeymanPearson lemma [312], decides for hypothesis $\mathcal{H}_{0}$ if $\Lambda(r)<\lambda$ and $\mathcal{H}_{1}$ otherwise, where $\lambda$ is some tunable threshold. The generalized version uses the on-line maximum-likelihood estimate $\widehat{\mu}_{1}$ of $\mu_{1}$ to allow the detection of a (possibly time-varying) change of unknown magnitude. The practical implementation using the log-likelihood ratio on $N$ observations is given by

$$
\left\{\sum_{t=1}^{N} r(t)<\frac{\sigma_{0}^{2}}{\hat{\mu}_{1}-\mu_{0}} \ln (\lambda)+\frac{N\left(\mu_{0}-\widehat{\mu}_{1}\right)}{2} \Longrightarrow \operatorname{\text {else}\Longrightarrow \text {decide}\mathcal {H}_{1}} \Longrightarrow \text { decide } \mathcal{H}_{0}\right.
$$

\subsection{Sequential probability ratio test}

The sequential probability ratio test is very similar to the generalized likelihood ratio, as it also uses the likelihood ratio. However, the minimum size of changes to be detected $\mu_{1}$ has to be specified, and the threshold $\lambda$ is fully determined by fixing the desired false-alarm probability $p_{\mathrm{fa}}$ and non-detection probability $p_{\text {nd }}>[\mathbf{5}]$. The following decisions are taken at each step

$$
\left\{\begin{array}{cc}
\Lambda(r)<\frac{p_{\text {nd }}}{1-p_{\text {fa }}} & \Longrightarrow \text { decide } \mathcal{H}_{0} \\
\Lambda(r)>\frac{1-p_{\text {dd }}}{p_{\text {fa }}} & \Rightarrow \text { decide } \mathcal{H}_{1} \\
\text { else } & \text { take no decision }
\end{array}\right.
$$

This test introduces a $\ll$ no decision $\gg$ option, where more data are requested to decide between $\mathcal{H}_{0}$ and $\mathcal{H}_{1}$. In the context of diagnosis, this can be interpreted as non-faulty behaviour, i.e. $\mathcal{H}_{0}$.

\subsection{CUSUM test}

Few statistical hypothesis are needed for this twosided test, which is expressed as follows $[\mathbf{5}, \mathbf{7}]$ 


$$
\left\{\begin{array}{l}
S_{1}(t)=\max \left(S_{1}(t-1)+r(t)-\mu_{0}-\mu_{1} / 2,0\right) \\
S_{2}(t)=\max \left(S_{2}(t-1)-r(t)+\mu_{0}-\mu_{1} / 2,0\right)
\end{array}\right.
$$

where $\mu_{1}$ is the minimal size of the fault to be detected. The decision rule is then

$$
\left\{\begin{array}{c}
\left(S_{1}>\lambda\right) \text { or }\left(S_{2}>\lambda\right) \Longrightarrow \text { decide } \mathcal{H}_{1} \\
\text { else } \Longrightarrow \text { decide } \mathcal{H}_{0}
\end{array}\right.
$$

where $\lambda$ is again some tunable threshold, reflecting the desired false-alarm rate.

\subsection{Randomised subsampling}

This method, proposed recently in reference [313], uses $M$ subsamplings of the signal on $N$ observations. The sum of the errors with respect to the expected mean $\mu_{0}$ is computed on each subsample. The decision is $\mathcal{H}_{0}$ if at least $L$ of the $M$ sums are greater than zero and at least $L$ of the $M$ sums are smaller than zero, else the decision is $\mathcal{H}_{1}$. An interesting property of the test is that the expected probability of false alarm is intrinsically equal to $2 L / M$.

\section{DISCUSSION}

\subsection{FDI methods: the case of civil aviation}

Focusing on the particular case of civil aviation (based on papers [73-107]), Table 6 presents different types of faults that have been studied in the literature and states the methods that have been employed to detect them, among those presented in section 4 . Advantages and drawbacks that have been reported for each method are also indicated. It should be noted that these conclusions are only partial, as none of these papers can claim to have compared all methods that could be applied on the test cases considered. Suggestions on how fair comparisons could be conducted are discussed at the end of the paper.

\subsection{Current industrial practice}

It is widely acknowledged by academic researchers and industrials that there is still a wide gap between state-of-the-art research in FDI and current industrial practice [34]. Within the few actually implemented schemes, diagnosis is generally part of an Integrated Vehicle Health Management (IVHM) system [314], which also includes prognosis and maintenance planning. The diagnosis methods employed in this context usually rely on hardware redundancy or simple limit checking of sensor outputs with threshold values fixed on the basis of recorded flight data [2].

As an illustration of embedded fault diagnosis in the civil aviation industry, comparable strategies have been patented by Boeing [315-317] and Airbus
[318-320]. In reference [315], Boeing proposes a voting scheme between the two redundant parts of a flight control surface with two redundant controllers, a limit-checking technique in reference [316] for redundant sensor values, while in reference [317] extra control signals with negligible impact on aircraft motion in fault-free condition, are sent to the flight control surfaces to highlight faults. Airbus developed in reference [318] a voting scheme between redundant power supplies of an aircraft and described fault-tolerant redundant flaps in reference [319]. In reference [320], the use of SVM is advocated to analyse data from built-in tests of sensors and estimate the actual time of occurrence of a fault.

The recent introduction of fly-by-wire electrical control systems in civil aviation have motivated several studies on model-based fault diagnosis by the aforementioned companies. The concern for faster, cleaner, and more energy-efficient aircraft has also made essential the use of analytical redundancy to reduce the number of redundant components and thus the aircraft mass [3]. This has, for example, led to the use of an observer-based oscillatory failure detection scheme which is actually embedded in A380 aircraft [104].

There seems to be a general agreement in the space industry on the use of IVHM architectures. Indeed, schemes developed by Astrium [321], CNES [322], NASA [323] or Thales Alenia Space $[\mathbf{4}, \mathbf{3 2 4}]$ generally involve hardware redundancy of subsystems, managed in an upper layer so as to provide a comprehensible decision. Parallel projects have been launched by ESA and NASA (see below) to investigate more elaborate model-based fault diagnosis strategies, though no embedded implementation has been reported yet.

A few projects have been launched to bring together academic and industrial engineers to assess various FDI methods on realistic simulators or real subsystems (e.g. ESA SMART-FDIR [325] or COMPASS [326], NASA X-37 [327] and parts of CxP [328] or European projects GARTEUR [32] ADDSAFE [329]). To reduce the gap between academic results and industrial end-users, these projects involve functional engineering simulators such as pilot-in-theloop or aircraft-in-the-loop testbeds. This should help advanced model-based fault diagnosis methods to face certification issues (some of which are hinted at in references $[\mathbf{3}, \mathbf{3 3 0}])$.

\subsection{Concluding remarks}

A generic, yet realistic, modelling of the dynamics of aerospace vehicles has been presented in this article. Fault modes that may affect their sensors and 
Table 6 Civil aviation faults and methods employed to detect them

\begin{tabular}{|c|c|c|c|}
\hline Method & Type of faults and references & Advantages as reported in papers & Drawbacks as reported in papers \\
\hline $\begin{array}{l}\text { Luenberger } \\
\text { observers }\end{array}$ & 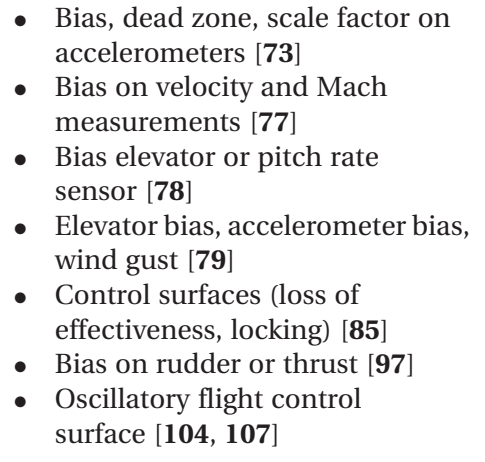 & $\begin{array}{l}\text { - Small false alarm rate } \\
\text { - Short detection delay } \\
\text { - Some robustness to model } \\
\text { uncertainty } \\
\text { - Isolation of simultaneous faults }\end{array}$ & $\begin{array}{l}\text { - } \quad \text { Computational burden } \\
\text { foultways easy to distinguish } \\
\text { disturbances (except with UIO) }\end{array}$ \\
\hline Kalman filters & $\begin{array}{ll}\text { - } & \text { Failures of sensors in an } \\
& \text { engine [91] } \\
\text { - } & \text { Locked aileron [105] } \\
\text { - } & \text { Bias in IMU/INS [106] } \\
\text { - } & \text { Bias on sensor in } \\
& \text { electromechanical flight } \\
& \text { control surface }[\mathbf{1 0 3}]\end{array}$ & $\begin{array}{l}\text { - Same advantages as Luenberger } \\
\text { observers } \\
\text { - Gaussian measurement noise } \\
\text { and state perturbations taken } \\
\text { into account }\end{array}$ & $\begin{array}{l}\text { Well-established for linear(ized) } \\
\text { models only } \\
\text { - Gaussian assumptions not } \\
\text { always valid }\end{array}$ \\
\hline Particle filter & - Bias in IMU sensor $[\mathbf{9 3}]$ & $\begin{array}{l}\text { - Non-linear model taken into } \\
\text { account } \\
\text { - Non-Gaussian noise can be } \\
\text { dealt with }\end{array}$ & $\begin{array}{l}\text { - Huge computational cost } \\
\text { - Knowledge of statistical } \\
\text { distribution of noise required }\end{array}$ \\
\hline $\mathcal{H}_{\infty}$ filters & $\begin{array}{l}\text { - } \text { Rudder loss of effectiveness [76] } \\
\text { - } \text { effevator and throttle loss of } \\
\text { - } \text { Bias on IMU or rudders [84] } \\
\text { - } \text { Intermittent bias on pitch rate } \\
\text { measurement }[\mathbf{9 6}]\end{array}$ & $\begin{array}{l}\text { - Worst-case robustness to } \\
\text { disturbances } \\
\text { - Possible estimation of } \\
\text { fault magnitude }\end{array}$ & $\begin{array}{l}\text { - Limited to linear or linear } \\
\text { parameter varying models } \\
\text { under standard form } \\
\text { - Conservative design }\end{array}$ \\
\hline $\begin{array}{l}\text { Sliding mode } \\
\text { observers }\end{array}$ & $\begin{array}{ll}\text { - } & \text { Biases in IMU or ADS [86] } \\
\text { - } & \text { Drift in rudder and throttle [88] } \\
& \text { Engine separation, rudder loss of } \\
& \text { effectiveness }[\mathbf{1 0 0}]\end{array}$ & $\begin{array}{l}\text { - Fault estimation } \\
\text { - Quick convergence } \\
\text { - Estimation of some disturbances }\end{array}$ & $\begin{array}{l}\text { - Computational burden } \\
\text { - Difficult tuning }\end{array}$ \\
\hline $\begin{array}{l}\text { Bounded-error } \\
\text { observer }\end{array}$ & $\begin{array}{l}\text { - } \quad \text { Bias on rudders }[\mathbf{8 9}] \\
\text { - Locking of actuator, bias on } \\
\text { speed sensor }[\mathbf{1 0 1}]\end{array}$ & $\begin{array}{l}\text { - Non-linear model taken into } \\
\text { account } \\
\text { - Very few false alarm } \\
\text { - Disturbances taken into account }\end{array}$ & $\begin{array}{l}\text { - Computational burden } \\
\text { - Detection delay (conservative } \\
\text { design) }\end{array}$ \\
\hline $\begin{array}{l}\text { NL geometric } \\
\text { observer }\end{array}$ & $\begin{array}{l}\text { - Locking/hardover/loss of } \\
\text { effectivenes of elevator or } \\
\text { throttle }[\mathbf{9 0}]\end{array}$ & $\begin{array}{l}\text { - Non-linear model taken into } \\
\text { account } \\
\text { - Fault isolation }\end{array}$ & $\begin{array}{l}\text { - System-dependent design } \\
\text { - Computational cost }\end{array}$ \\
\hline $\begin{array}{l}\text { Parameter } \\
\text { estimation }\end{array}$ & $\begin{array}{l}\text { - Wing damage, rudder } \\
\text { locking }[\mathbf{8 0}] \\
\text { - Wing damage }[\mathbf{9 9}] \\
\text { - } \quad \text { Icing }[\mathbf{1 0 2}]\end{array}$ & $\begin{array}{l}\text { - Appropriate to structural damage } \\
\text { detection }\end{array}$ & $\begin{array}{l}\text { - On-line identification time } \\
\text { - Less appropriate to sensor or } \\
\text { actuator fault isolation }\end{array}$ \\
\hline Neural networks & $\begin{array}{l}\text { - } \text { Bias/drift of IMU sensors or } \\
\text { actuator [75] } \\
\text { - Tail or wing damage [82] } \\
\text { - Elevator bias [87] }\end{array}$ & - Dynamical model not required & $\begin{array}{l}\text { - Choice of network structure may } \\
\text { be difficult } \\
\text { - Huge on-line learning time } \\
\text { - Learning convergence not } \\
\text { guaranteed }\end{array}$ \\
\hline PCA & $\begin{array}{l}\text { - Wing damage }[\mathbf{9 5}] \\
\text { - Bias in engine components [98] }\end{array}$ & - No dynamical model & $\begin{array}{l}\text { - Restricted to linear dependence } \\
\text { between variables } \\
\text { - Required training data }\end{array}$ \\
\hline SVM & $\begin{array}{l}\text { - Bias of rudder or angle-of-attack } \\
\text { sensor [92] }\end{array}$ & - Linearity of the prediction & $\begin{array}{l}\text { - Required training data } \\
\text { - Limited to known classes of faults }\end{array}$ \\
\hline Expert system & - Engine separation [74] & - Small computational cost & - Very system-dependent \\
\hline
\end{tabular}


actuators have been discussed and modelled. The key points of FDD approaches that are applicable in this context have been explained, focusing on modelbased methods but also including a short overview of model-free methods that may be useful when models are inaccurate or unavailable. This presentation, supported by a large bibliographical review, provides a synthetic view of recent applications of FDD methods in aerospace. Table 4 , which relates the classes of FDI methods and the types of aerospace vehicles on which they have been applied, seems particularly relevant for this purpose. What appears is that no specific method is dedicated to a single type of system, since their dynamic models are sufficiently generic to make the same procedures applicable. However, with this article, engineers that are interested in a specific type of vehicle can have a quick access to FDI methods that are being applied on similar systems. The fact that similar methods have been used to address different types of vehicles confirms the genericity of the modelling presented.

Parameter estimation (section 4.2) is well suited to detect structural changes, while other model-based methods (sections 4.3 to 4.6 ) are more interesting for detecting faults on sensors and actuators. Some qualitative elements of comparison between methods can be found in references $[\mathbf{1 9 - 2 2 , ~ 2 5 , ~ 2 6 ] . ~ T h e ~}$ most versatile approaches appear to be using banks of observers or Kalman filters (section 4.3), since they can handle any type of fault and make it possible to generate structured residuals that facilitate fault isolation. However, they require a large modelling effort and imply a heavy computational cost with respect to the resources available on-board. For example, single fault monitoring on classical state variables of an aeronautical model requires the numerical integration of 12 filters, and each filter provides 12 residuals. Alternative solutions should be developed, in parallel with increasing embedded computational ability.

Relying directly on fault estimation instead of residuals is attractive, since it makes the decision logic lighter (a fault-incidence matrix is no longer needed). There has been a trend in this direction, especially with the introduction of sliding-mode observers and geometrical approaches for nonlinear systems. Moreover, this approach is well suited to address reconfiguration of the control law of the system and achieve fault tolerance [331].

The highly non-linear dynamics governing aerospace models (section 3 ) limits the range of applicable methods using an explicit knowledge-based dynamical model. Linearization or polynomial approximation only add more uncertainty to an already inaccurate model. Despite this widespread observation, most applications use linear models or linearization: 29 per cent of the papers reported in Table 4 used linear models, 46 per cent linearized methods and only 25 per cent non-linear approaches. Though there has been a trend towards extension to non-linear controlaffine systems, which often seems an acceptable modelling trade-off to represent the behaviour of flight vehicles. More applications should be developed in this direction. Non-linear FDI is still ongoing research, as is non-linear observer theory, and aeronautical applications can motivate interesting developments in both fields. In particular, various decoupling strategies have been proposed to deal with uncertainty and disturbances (section 4.5). UIO and geometric approaches are particularly promising, but their applicability to non-linear aircraft remains to be confirmed. The assumption of bounded errors is also an attractive way to handle uncertainty in a non-linear context.

An interesting property of aerospace dynamical models that could be exploited more efficiently for diagnosis is that the kinematics equations (1) and (3) do not involve control inputs. These relations provide analytical redundancy that may be used to detect sensor faults. Similarly, faults on actuators can be detected using force and momentum equations (4) and (11) only.

Reliability of the knowledge about the system is a major criterion for method selection. Models described in section 3 have been validated by previous works in flight mechanics, even though their inner parameters may be inaccurate in actual flight conditions, especially aerodynamic coefficients whose in-flight variations are not well known. Modern pattern recognition approaches (section 4.1) could be of great help to increase diagnosis robustness to these sources of uncertainty. Nevertheless, these techniques cannot be used alone when no specific record is available before the mission, and prior knowledge on the dynamics of the system should not be ignored. An interesting approach would be to assist a modelbased algorithm with a model-free one, based on in-flight measurements. A line of inquiry may be given by a semi-parametric kernel machine taking into account the influences of both model and measurements to regularize estimation.

It must also be kept in mind that flight vehicles are closed-loop controlled, which may lessen the impact of failing components by modifying the fault dynamics. This may be taken into account in the design of fault detection methods that will test consistency between computed control inputs (i.e. controller outputs) and the control inputs actually achieved, as estimated from measured system outputs. It is even possible to design control inputs in such a way as to facilitate FDI, or to use the adequacy with control objectives to detect faults. These control-related 
strategies (section 4.6) are just beginning to be investigated and already show great potential.

There is a rising interest from industry in advanced model-based strategies to cope with the drawbacks of classical hardware redundancy and threshold management techniques (section 6.2). To validate these new approaches, there is the need for actual flight tests, since most work is done in simulation (admittedly with increasing realism). It is already interesting to assess that a fault diagnosis algorithm raises no false alarm in normal operation.

Concerning residual evaluation strategies, statistical tests should generally be preferred to fixed thresholds that may become unreliable due to uncertainty, or on the contrary too conservative. The CUSUM test is widely used, and has demonstrated good abilities in quantitative comparisons on typical test cases $[5,332]$.

Finally, an objective evaluation of the various methods on benchmarks is necessary in order to build an efficient FDI aircraft methodology. Methodindependent performance indices such as those defined in section 2.4 can be used as objectives to be optimized. All the FDI strategies considered have some internal parameters that need to be chosen. To compare these strategies as objectively as possible, these inner parameters should be systematically tuned to achieve optimality in terms of the performance indices. The design of such a procedure has been addressed as a global optimization problem solved via robust surrogate-based optimization in references $[\mathbf{3 3 2}, \mathbf{3 3 3}]$ and shown promising results.

\section{FUNDING}

This research received no specific grant from any funding agency in the public, commercial, or notfor-profit sectors.

\section{ACKNOWLEDGEMENT}

This work was supported by ONERA - The French Aerospace Lab.

(C) IMechE 2011

\section{REFERENCES}

1 Schaefer, R. Unmanned aerial vehicle reliability study, 2003 (Office of the Secretary of Defense, Washington, DC).

2 Johnson, D. M. A review of fault management techniques used in safety-critical avionic systems. Prog. Aerosp. Sci., 1996, 32(5), 415-431.

3 Goupil, P. AIRBUS state of the art and practices on FDI and FTC. In Proceedings of the 7th IFAC
Symposium on Fault detection, supervision and safety of technical processes, Barcelona, Spain, 1-3 July 2009, pp. 564-572.

4 Olive, X. FDI(R) for satellite at Thales Alenia Space: how to deal with high availability and robustness in Space domain? In Proceedings of the IEEE Conference on Control and fault-tolerant systems, SysTol'10, Nice, France, 6-8 October 2010, pp. 837842.

5 Basseville, M. and Nikiforov, I. V. Detection of abrupt changes: theory and application, 1993 (Prentice Hall, Englewood Cliffs, NJ).

6 Patton, R. J. and Frank, P. M. Issues of fault diagnosis for dynamic systems., 2000 (Springer-Verlag, London).

7 Gustafsson, F. Adaptive filtering and change detection, 2001 (Wiley, London).

8 Blanke, M., Kinnaert, M., Lunze, J., and Staroswiecki, M. Diagnosis and fault-tolerant control, 2003 (Springer-Verlag, Berlin Heidelberg).

9 Simani, S., Fantuzzi, C., and Patton, R. J. Modelbased fault diagnosis in dynamic systems using identification techniques, 2003 (Springer-Verlag, London).

10 Isermann, R. Fault-diagnosis systems: an introduction from fault detection to fault tolerance, 2006 (Springer-Verlag, Berlin Heidelberg).

11 Witczak, M. Modelling and estimation strategies for fault diagnosis of nonlinear systems: from analytical to soft computing approaches, 2007 (SpringerVerlag, Berlin/Heidelberg).

12 Ding, S. X. Model-based fault diagnosis techniques: design schemes, algorithms, and tools, 2008 (Springer-Verlag, Berlin/Heidelberg).

13 Willsky, A. S. A survey of design methods for failure detection in dynamic systems. Automatica, 1976, 12(6), 601-611.

14 Chow, E. Y. and Willsky, A. S. Analytical redundancy and the design of robust failure detection systems. IEEE Trans. Autom. Control, 1984, 29(7), 603-614.

15 Isermann, R. Process fault detection based on modelling and estimation methods-a survey. Automatica, 1984, 20(4), 387-404.

16 Gertler, J. J. Survey of model-based failure detection and isolation in complex plants. IEEE Control Syst. Mag., 1988, 8(6), 3-11.

17 Frank, P. M. Fault diagnosis in dynamic systems using analytical and knowledge-based redundancy: A survey and some new results. Automatica, 1990, 26(3), 459-474.

18 Isermann, R. Supervision, fault-detection and fault-diagnosis methods : An introduction. Control Eng. Pract., 1997, 5(5), 639-652.

19 Betta, G. and Pietrosanto, A. Instrument fault detection and isolation: State of the art and new research trends. IEEE Trans. Instrum. Meas., 2000, 49(1), 100-107.

20 Venkatasubramanian, V., Rengaswamy, R., Yin, K., and Kavuri, S. N. A review of process fault detection and diagnosis. Part I: Quantitative modelbased methods. Comput. Chem. Engng, 2003, 27(3), 293-311. 
21 Venkatasubramanian, V., Rengaswamy, R., and Kavuri, S. N. A review of process fault detection and diagnosis. Part II: Qualitative models and search strategies. Comput. Chem. Engng, 2003, 27(3), 313-326.

22 Venkatasubramanian, V., Rengaswamy, R., Kavuri, S. N., and Yin, K. A review of process fault detection and diagnosis. Part III: Process history based methods. Comput. Chem. Engng, 2003, 27(3), 327-346.

23 Kinnaert, M. Fault diagnosis based on analytical models for linear and nonlinear systems-a tutorial. In Proceedings of the 5th IFAC Symposium on Fault detection, supervision and safety of technical processes, Washington DC, USA, 9-11 June 2003, pp. 37-50.

24 Isermann, R. Model-based fault-detection and diagnosis-status and applications. Ann. Rev. Control, 2005, 29(1), 71-85.

25 Zhang, Y. and Jiang, J. Bibliographical review on reconfigurable fault-tolerant control systems. Ann. Rev. Control, 2008, 32(2), 229-252.

26 Hwang, I., Kim, S., Kim, Y., and Seah, C. E. A survey of fault detection, isolation, and reconfiguration methods. IEEE Trans. Control Syst. Technol., 2010, 18(3), 636-653.

27 Frank, P. M. Advanced fault diagnosis techniques in aerospace systems. In Proceedings of CompEuro '89. VLSI and Computer Peripherals, Hamburg, Germany, 8-12 May 1989, vol. 3, pp. 136-143.

28 Patton, R. J. Fault detection and diagnosis in aerospace systems using analytical redundancy. Comput. Control Engng J., 1991, 2(3), 127-136.

29 Patton, R. J. and Chen, J. Review of parity space approaches to fault diagnosis for aerospace systems. J. Guid. Control Dyn., 1994, 17, 278-285.

30 Hajiyev, C. and Caliskan, F. Fault diagnosis and reconfiguration in flight control systems, 2003 (Kluwer Academic Publishers, London).

31 Henry, D. From fault diagnosis to recovery actions for aeronautic and aerospace missions: a modelbased point of view. In Proceedings of the 23rd IAR Workshop on Advanced control and diagnosis, Coventry, UK, 27-28 November 2008.

32 Edwards, C., Lombaerts, T., and Smaili, H. Fault tolerant flight control: a benchmark challenge, 2010 (Springer Verlag, Berlin Heidelberg).

33 Meskin, N. and Khorasani, K. Fault detection and isolation: multi-vehicle unmanned systems, 2011 (Springer, New York).

34 Zolghadri, A. The challenge of advanced modelbased FDIR techniques for aerospace systems the 2011 situation. In Proceedings of the 4th European Conference for Aero-Space Sciences, EUCASS 2011, St-Petersburg, Russia, 4-8 July 2011.

35 Isermann, R. and Balle, P. Trends in the application of model-based fault detection and diagnosis of technical processes. Control Eng. Pract., 1997, 5(5), 709-719.

36 Bartyś, M., Patton, R. J., Syfert, M., de las Heras, S., and Quevedo, J. Introduction to the DAMADICS actuator FDI benchmark study. Control Eng. Pract., 2006, 14(6), 577-596.
37 Frank, P. M. Handling modelling uncertainty in fault detection and isolation systems. J. Control Engng Appl. Inform., 2002, 4(4), 29-46.

38 Saif, M. and Guan, Y. A new approach to robust fault detection and identification. IEEE Trans. Aerosp. Electron. Syst., 1993, 29(3), 685-695.

39 Chen, J., Patton, R. J., and Liu, G. P. Detecting incipient sensor faults in flight control systems. In Proceedings of the 3rd IEEE Conference on Control applications, Glasgow, Scotland, 24-26 August 1994, vol. 2, pp. 871-876.

40 Melody, J. W., Hillbrand, T., Baar, T., and Perkins, W. R. $\mathcal{H}_{\infty}$ parameter identification for in-flight detection of aircraft icing: the time-varying case. Control Eng. Pract., 2001, 9(12), 1327-1335.

41 De Persis, C., De Santis, R., and Isidori, A. Nonlinear actuator fault detection and isolation for a VTOL aircraft. In Proceedings of the American Control Conference, Arlington, USA, 25-27 June 2001, vol. 6, pp. 4449-4454.

42 Magrabi, S. M. and Gibbens, P. W. Decentralised fault detection and diagnosis in navigation systems for unmanned aerial vehicles. In Proceedings of the IEEE Position Location and Navigation Symposium, San Diego, USA, 24-26 April 2002, pp. 363-370.

43 Miller, R. H. and Larsen, M. L. Optimal fault detection and isolation filters for flight vehicle performance monitoring. In Proceedings of the 2003 IEEE Aerospace Conference, Big Sky, USA, 8-15 March 2003, vol. 7, pp. 3197-3203.

44 Park, T. G. and Lee, K. S. Process fault isolation for linear systems with unknown inputs. IET Control Theory Applic., 2004, 151, 720-726.

45 Kim, H. S., Park, S. K., Kim, Y., and Park, C. G. Hybrid fault detection and isolation method for UAV inertial sensor redundancy management system. In Proceedings of the 16th IFAC World Congress, Prague, Czech Republic, 3-8 July 2005, pp. 265-270.

46 Mattei, M., and Paviglianiti, G. Managing sensor hardware redundancy on a small commercial aircraft with $\mathcal{H}_{\infty}$ FDI observers. In Proceedings of the 16th IFAC World Congress, Prague, Czech Republic, 3-8 July 2005, pp. 347-352.

47 Mattei, M., and Paviglianiti, G. Online approximators for the actuators FDI of a small commercial aircraft. In Proceedings of the 16th IFAC World Congress, Prague, Czech Republic, 3-8 July 2005, pp. 336-341.

48 Amato, F., Cosentino, C., Mattei, M., and Paviglianiti, G. A direct/functional redundancy scheme for fault detection and isolation on an aircraft. Aerosp. Sci. Technol., 2006, 10(4), 338-345.

49 Bonfe, M., Castaldi, P., Geri, W., and Simani, S. Fault detection and isolation for on-board sensors of a general aviation aircraft. Int. J. Adaptive Control Signal Process., 2006, 20(8), 381-408.

50 Bo, Y., Yongyuan, Q., and Yan, C. A method for fault detection and isolation in the integrated navigation system for UAV. Meas. Sci. Technol., 2006, 17(6), 1522-1528.

51 Rotstein, H. P., Ingvalson, R., Keviczky, T., and Balas, G. J. Fault-detection design for uninhabited 
aerial vehicles. J. Guid. Control Dyn., 2006, 29(5), 1051-1060.

52 Kim, S., Kim, Y., Park, C. G., and Jung, I. Hybrid fault detection and isolation techniques for aircraft inertial measurement sensors. Int. J. Aeronaut. Space Sci., 2006, 7(1), 73-83.

53 Slegers, N. and Costello, M. Variable structure observer for control bias on unmanned air vehicles. J. Guid. Control Dyn., 2007, 30(1), 281-286.

54 Sharma, R. and Aldeen, M. Fault detection in nonlinear systems with unknown inputs using sliding mode observer. In Proceedings of the American Control Conference, New York City, USA, 11-13 July 2007, pp. 432-437.

55 Bonfe, M., Castaldi, P., Geri, W., and Simani, S. Nonlinear actuator fault detection and isolation for a general aviation aircraft. Space Technol., 2007, 27(2-3), 107-114.

56 Benini, M., Bonfe, M., Castaldi, P., Geri, W., and Simani, S. Fault diagnosis strategies for a simulated nonlinear aircraft model. In Proceedings of the 17th IFAC World Congress, Seoul, Republic of Korea, 6-11 July 2008, pp. 7300-7307.

57 Bateman, F., Noura, H., and Ouladsine, M. Active fault detection and isolation strategy for an unmanned aerial vehicle with redundant flight control surfaces. In Proceedings of the 16th Mediterranean Conference on Control and automation, Ajaccio, France, 25-27 June 2008, pp. 1246-1251.

58 Ducard, G. and Geering, H. P. Efficient nonlinear actuator fault detection and isolation system for unmanned aerial vehicles. J. Guid. Control Dyn., 2008, 31(1), 225-237.

59 Castaldi, P., Geri, W., Bonfe, M., Simani, S., and Benini, M. Design of residual generators and adaptive filters for the FDI of aircraft model sensors. Control Eng. Pract., 2010, 18(5), 449-459.

60 Samy, I., Postlethwaite, I., and Gu, D. W. Sensor fault detection and accommodation using neural networks with application to a nonlinear unmanned air vehicle model. Proc. IMechE, Part G: J. Aerospace Engineering, 2010, 224(4), 437-447.

61 Dimogianopoulos, D., Hios, J., and Fassois, S. Aircraft engine health management via stochastic modelling of flight data interrelations. Aerosp. Sci. Technol., 2011, in press DOI: 10.1016/ j.ast.2011.03.002.

62 Drozeski, G. R., Saha, B., and Vachtsevanos, G. J. A fault detection and reconfigurable control architecture for unmanned aerial vehicles. In Proceedings of the 2005 IEEE Aerospace Conference, Big Sky, USA, 5-12 March 2005, pp. 1-9.

63 Rafaralahy, H., Richard, E., Boutayeb, M., and Zasadzinski, M. Simultaneous observer based sensor diagnosis and speed estimation of unmanned aerial vehicle. In Proceedings of the 47th IEEE Conference on Decision and control, 911 December 2008, pp. 2938-2943.

64 Berbra, C., Gentil, S., and Lesecq, S. Identification of multiple faults in an inertial measurement unit. In Proceedings of the 7th Workshop on Advanced control and diagnosis ACD'2009, Zielona Gora, Poland, 19-20 November 2009.

65 Zhang, N., Fernandez, J. L. L., Doncescu, A., and Mora-Camino, F. Rotorcraft fault detection using difference flatness. In Proceedings of the AIAA Guidance, Navigation, and Control Conference, Chicago, USA, 10-13 August 2009.

66 Freddi, A., Longhi, S., and Monteriu, A. A modelbased fault diagnosis system for unmanned aerial vehicles. In Proceedings of the 7 th IFAC Symposium on Fault detection, supervision and safety of technical processes, Barcelona, Spain, 1-3 July 2009, pp. 71-76.

67 Nguyen, H. V., Berbra, C., Lesecq, S., Gentil, S., Barraud, A., and Godin, C. Diagnosis of an inertial measurement unit based on set membership estimation. In Proceedings of the 17th IEEE Mediterranean Conference on Control and automation, Thessaloniki, Greece, 24-26 June 2009, pp. 211-216.

68 Rag, C., Prasanth, R., Mehra, R. K., and Fortenbaugh, R. Failure detection and identification and fault tolerant control using the IMM-KF with applications to the eagle-eye UAV. In Proceedings of the 37th IEEE Conference on Decision and control, Tampa, USA, 16-18 December 1998, pp. 4208-4213.

69 Oza, N., Tumer, K., Tumer, I., and Huff, E. Classification of aircraft maneuvers for fault detection. In Multiple classifier systems, Vol. 2709 of Lecture Notes in Computer Science (Eds T. Windeatt and F. Roli), 2003, pp. 375-384 (Springer Verlag, Berlin/Heidelberg).

70 Samar, S., Gorinevsky, D., and Boyd, S. P. Embedded estimation of fault parameters in an unmanned aerial vehicle. In Proceedings of the IEEE International Conference on Control applications, Munich, Germany, 4-6 October 2006, pp. 3265-3270.

71 Achour, W., Piet-Lahanier, H., and Siguerdidjane, H. Bounded error identification of the wind gusts effect on a small scaled helicopter. In Proceedings of the IFAC Workshop on Aerospace guidance, navigation and flight control systems, Samara, Russia, 30 June-2 July 2009.

72 Heredia, G., Ollero, A., Bejar, M., and Mahtani, R. Sensor and actuator fault detection in small autonomous helicopters. Mechatronics, 2008, 18(2), 90-99.

73 Clark, R. N. Instrument fault detection. IEEE Trans. Aerosp. Electron. Syst., 1978, (3), 456-465.

74 Schutte, P. C., Abbott, K. H., Palmer, M. T., and Ricks, W. R.. An evaluation of a real-time fault diagnosis expert system for aircraft applications. In Proceedings of the IEEE Conference on Decision and control, Los Angeles, USA, 9-11 December 1987, vol. 26, pp. 1941-1947.

75 Napolitano, M. R., An, Y., and Seanor, B. A. A fault tolerant flight control system for sensor and actuator failures using neural networks. Aircraft Des., 2000, 3(2), 103-128. 
76 Wu, N. E., Zhou, K., and Salomon, G. Control reconfigurability of linear time-invariant systems. Automatica, 2000, 36(11), 1767-1771.

77 Zolghadri, A., Goetz, C., Bergeon, B., and Denoize, $\mathbf{X}$. Integrity monitoring of flight parameters using analytical redundancy. In Proceedings of the UKACC International Conference on Control, Sheffield, UK, 10-12 September 2002, pp. 1534-1539.

78 Szaszi, I., Kulcsar, B., Balas, G. J., and Bokor, J. Design of FDI filter for an aircraft control system. In Proceedings of the American Control Conference, Anchorage, USA, 8-10 May 2002, pp. 4232-4237.

79 Wilbers, D. M. and Speyer, J. L. Detection filters for aircraft sensor and actuator faults. In Proceedings of the IEEE International Conference on Control and applications, Jerusalem, Israel, 3-6 April 1989, pp. 81-86.

80 Glavaski, S., Elgersma, M., Dorneich, M., and Lommel, P. Failure accommodating aircraft control. In Proceedings of the American Control Conference, vol. 5, Anchorage, USA, 8-10 May 2002, pp. 3624-3630.

81 Glavaski, S. and Elgersma, M. Active aircraft fault detection and isolation. In Proceedings of IEEE Systems Readiness Technology Conference AUTOTESTCON, Valley Forge, USA, 21-24 October 2002, pp. 692-705.

82 Dasgupta, D., Krishnakumar, K., Wong, D., and Berry, M. Negative selection algorithm for aircraft fault detection. Artif. Immune Syst., 2004, 3239, $1-13$.

83 Szaszi, I., Marcos, A., Balas, G. J., and Bokor, J. Linear parameter-varying detection filter design for a Boeing 747-100/200 aircraft. J. Guid. Control Dyn., 2005, 28(3), 461-470.

84 Marcos, A., Ganguli, S., and Balas, G. J. An application of $\mathcal{H}_{\infty}$ fault detection and isolation to a transport aircraft. Control Eng. Pract., 2005, 13(1), 105-119.

85 Azam, M., Pattipati, K., Allanach, J., Poll, S., and Patterson-Hine, A. In-flight fault detection and isolation in aircraft flight control systems. In Proceedings of the 2005 IEEE Aerospace Conference, Big Sky, USA, 5-12 March 2005.

86 Alwi, H. and Edwards, C. Robust sensor fault estimation for tolerant control of a civil aircraft using sliding modes. In Proceedings of the American Control Conference, Minneapolis, USA, 14-16 June 2006, pp. 5704-5709.

87 Fekih, A., Xu, H., and Chowdhury, F. N. Two neural net-learning methods for model based fault detection. In Proceedings of the 6th IFAC Symposium on Fault detection supervision and safety for technical processes, Beijing, 30 August1 September 2006, pp. 72-77.

88 Liu, J., Jiang, B., and Zhang, Y. Sliding mode observer-based fault detection and isolation in flight control systems. In Proceedings of the IEEE International Conference on Control and applications, Singapore, 1-3 October 2007, pp. 1049-1054.

89 Ribot, P., Jauberthie, C., and Travé-Massuyes, L. State estimation by interval analysis for a nonlinear differential aerospace model. In Proceedings of the
IEEE European Control Conference, Kos, Greece, 2-5 July 2007, pp. 4839-4844.

90 Meskin, N., Jiang, T., Sobhani, E., Khorasani, K., and Rabbath, C. A. Nonlinear geometric approach to fault detection and isolation in an aircraft nonlinear longitudinal model. In Proceedings of the American Control Conference, New York City, USA, 11-13 July 2007, pp. 5771-5776.

91 Rausch, R. T., Goebel, K. F., Eklund, N. H., and Brunell, B. J. Integrated in-flight fault detection and accommodation: a model-based study. J. Engng Gas Turb. Power, 2007, 129(4), 962-969.

92 Yin, W., Zhang, W. G., and Sun, X. A SVM-based multiple faults classification scheme design in flight control FDI system. In Proceedings of the Second International Conference on Innovative computing information and control, Kumamoto, Japan, 5-7 September 2007, pp. 187-191.

93 Cheng, Q., Varshney, P. K., Michels, J. H., and Belcastro, C. M. Fault detection in dynamic systems via decision fusion. IEEE Trans. Aerosp. Electron. Syst., 2008, 44(1), 227.

94 Samara, P. A., Fouskitakis, G. N., Sakellariou, J. S., and Fassois, S. D. A statistical method for the detection of sensor abrupt faults in aircraft control systems. IEEE Trans. Control Syst. Technol., 2008, 16(4), 789-798.

95 Trendafilova, I., Cartmell, M. P., and Ostachowicz, W. Vibration-based damage detection in an aircraft wing scaled model using principal component analysis and pattern recognition. J. Sound Vibration, 2008, 313(3-5), 560-566.

96 Zhou, J. and Huang, X. Application of a new fault detection approach to aerocraft's closed-loop control system. Intell. Robot. Appl., 2008, 1223-1232.

97 Varga, A. Monitoring actuator failures for a large transport aircraft - the nominal case. In Proceedings of the 7th IFAC Symposium on Fault detection, supervision and safety of technical processes, Barcelona, Spain, 1-3 July 2009, pp. 627-632.

98 Borguet, S. and Leonard, O. Coupling principal component analysis and Kalman filtering algorithms for on-line aircraft engine diagnostics. Control Pract. Engng, 2009, 17(4), 494-502.

99 Smith, T. A., Nielsen, Z. A., Reichenbach, E. Y., and Sr, J. M. U. Dynamic structural fault detection and identification. In Proceedings of the AIAA Guidance, Navigation, and Control Conference, Chicago, USA, 10-13 August 2009.

100 Alwi, H., Edwards, C., Stroosma, O., and Mulder, J. Evaluation of a sliding mode fault-tolerant controller for the $\mathrm{El} \mathrm{Al} \mathrm{incident.} \mathrm{J.} \mathrm{Guid.} \mathrm{Control} \mathrm{Dyn.,} \mathrm{2010,}$ 33(3), 677-694.

101 Rosa, P., Silvestre, C., Shamma, J. S., and Athans, M. Fault detection and isolation of an aircraft using set-valued observers. In Proceedings of the 18th IFAC Symposium on Automatic control in aerospace, Nara, Japan, 6-10 September 2010.

102 Hardier, G. and Bucharles, A. On-line parameter identification for in-flight aircraft monitoring. In Proceedings of the 27th International Congress of the Aeronautical Sciences, Nice, France, 2010. 
103 Jayakumar, M. and Das, B. B. Isolating incipient sensor faults and system reconfiguration in a flight control actuation system. Proc. IMechE, Part G: J. Aerospace Engineering, 2010, 224(1), 101-111.

104 Goupil, P. Oscillatory failure case detection in the A380 electrical flight control system by analytical redundancy. Control Eng. Pract., 2010, 18(9), 1110-1119.

105 Döll, C., Hardier, G., Varga, A., and Kappenberger, C. IMMUNE project : an overview. In Proceedings of the 18th IFAC Symposium on Automatic control in aerospace, Nara, Japan, 6-10 September 2010.

106 Berdjag, D., Zolghadri, A., Cieslak, J., and Goupil, P. Fault detection and isolation for redundant aircraft sensors. In Proceedings of the IEEE Conference on Control and fault-tolerant systems, SysTol'10, Nice, France, 6-8 October 2010, pp. 137-142.

107 Efimov, D., Zolghadri, A., and Raïssi, T. Actuator fault detection and compensation under feedback control. Automatica, 2011, 47(8), 1699-1705 (in press.

108 Eide, P. K. and Maybeck, P. S. An MMAE failure detection system for the F-16. IEEE Trans. Aerosp. Electron. Syst., 1996, 32(3), 1125-1136.

109 Monaco, J., Ward, D., Barron, R., and Bird, R. Implementation and flight test assessment of an adaptive, reconfigurable flight control system. In Proceedings of the AIAA Guidance, Navigation, and Control Conference, New Orleans, Louissiana LA, 11-13 August 1997, pp. 97-3738.

110 Hajiyev, C. and Caliskan, F. Sensor/actuator fault diagnosis based on statistical analysis of innovation sequence and robust Kalman filtering. Aerosp. Sci. Technol., 2000, 4(6), 415-422.

111 Caliskan, F. and Hajiyev, C. M. Innovation sequence application to aircraft sensor fault detection: comparison of checking covariance matrix algorithms. ISA Trans., 2000, 39(1), 47-56.

112 Chen, Y. M. and Lee, M. L. Neural networks-based scheme for system failure detection and diagnosis. Math. Comput. Simul., 2002, 58(2), 101-109.

113 Menke, T. E. and Maybeck, P. S. Sensor/actuator failure detection in the Vista F-16 by multiple model adaptive estimation. IEEE Trans. Aerosp. Electron. Syst., 2002, 31(4), 1218-1229.

114 Chen, R. H. and Speyer, J. L. Sensor and actuator fault reconstruction. J. Guid. Control Dyn., 2004, 27(2), 186-196.

115 Hagenblad, A., Gustafsson, F., and Klein, I. A comparison of two methods for stochastic fault detection: the parity space approach and principal component analysis. In Proceedings of 13th IFAC Symposium on System identification 2003, Rotterdam, The Netherlands, 27-29 August 2003.

116 Chen, B. and Nagarajaiah, S. Linear-matrixinequality-based robust fault detection and isolation using the eigenstructure assignment method. J. Guid. Control Dyn., 2007, 30(6), 1831-1835.

117 Wang, D. and Lum, K. Y. Adaptive unknown input observer approach for aircraft actuator fault detection and isolation. Int. J. Adaptive Control Signal Process., 2007, 21(1), 31-48.

118 Kim, S. and Choi, J. Fault detection and diagnosis of aircraft actuators using fuzzy-tuning IMM filter. IEEE Trans. Aerosp. Electron. Syst., 2008, 44(3), 940-952.

119 Fravolini, M. L., Brunori, V., Campa, G., Napolitano, M. R., and Cava, M. L. Structural analysis approach for the generation of structured residuals for aircraft FDI. IEEE Trans. Aerosp. Electron. Syst., 2010, 45(4), 1466-1482.

120 Burcham, F. W., Maine, T. A., and Fullerton, C. G. Development and flight evaluation of an emergency digital flight control system using only engine thrust on an F-15 airplane, 1996 (NASA, TP-3627).

121 Ostroff, A. J. and Bacon, B. J. Force and moment approach for achievable dynamics using nonlinear dynamic inversion. In AIAA Guidance, Navigation, and Control Conference, Portland, Oregon, 9-12 August 1999, pp. 424-434.

122 Ostroff, A. J. and Bacon, B. J. Reconfigurable flight control using nonlinear dynamic inversion with a special accelerometer implementation. In Proceedings of the AIAA Guidance, Navigation, and Control Conference, Denver, USA, 14-17 August 2000.

123 Zhang, Y. and Li, X. R. Detection and diagnosis of sensor and actuator failures using IMM estimator. IEEE Trans. Aerosp. Electron. Syst., 1998, 34(4), 1293-1313.

124 Scholte, E. and Campbell, M. E. On-line nonlinear guaranteed estimation with application to a high performance aircraft. In Proceedings of the American Control Conference, Anchorage, USA, 8-10 May 2002, pp. 184-190.

125 Boskovic, J. D., Bergstrom, S. E., Mehra, R. K., Co, S. S., and Woburn, M. A. Retrofit reconfigurable flight control in the presence of control effector damage. In Proceedings of the American Control Conference, Portland, USA, 8-10 June 2005, pp. 2652-2657.

126 Benitez-Pérez, H., Garcia-Nocetti, F., and Thompson, H. Fault classification based upon self organizing feature maps and dynamic principal component analysis for inertial sensor drift. Int. J. Innov. Comput. Inform. Control, 2007, 3(2), 257-276.

127 Yan, X. G. and Edwards, C. Robust sliding mode observer-based actuator fault detection and isolation for a class of nonlinear systems. Int. J. Syst. Sci., 2008, 39(4), 349-359.

128 Fravolini, M. L. and Campa, G. Design of robust redundancy relations for a semi-scale YF-22 aircraft model. Control Eng. Pract., 2009, 17(7), 773-786.

129 Kerr, M. L., Marcos, A., Penin, L. F., Briege, O., Postlethwaite, I., and Turner, M. Piloted assessment of a fault diagnosis algorithm on the ATTAS aircraft. In Proceedings of the AIAA Guidance, Navigation, and Control Conference, Chicago, USA, 10-13 August 2009.

130 Chen, W. H. Nonlinear disturbance observerenhanced dynamic inversion control of missiles. J. Guid. Control Dyn., 2003, 26(1), 161-166. 
131 Xu, D., Wu, M., and An, J. Design of an expert system based on neural network ensembles for missile fault diagnosis. In Proceedings of the IEEE Conference on Robotics, intelligent systems and signal processing, vol. 2, Las Vegas, USA, 8-13 October 2003, pp. 903-908.

132 Halder, P., Chaudhuri, S. K., and Mukhopadhyay, S. On line sensor fault detection, isolation and accommodation in tactical aerospace vehicle. In Proceedings of the IEEE TENCON, Chiang Mai, Thailand, 24 November 2004, pp. 684-686.

133 Yu, C., Han, H. X., and Min, W. Missile fault detection based on linear parameter varying fault detection filter. Inform. Technol. J., 2009, 8(3), 340-346.

134 Marzat, J., Piet-Lahanier, H., Damongeot, F., and Walter, E. A new model-free method performing closed-loop fault diagnosis for an aeronautical system. In Proceedings of the 7th Workshop on Advanced control and diagnosis, ACD'2009, Zielona Gora, Poland, 19-20 November 2009.

135 Marzat, J., Piet-Lahanier, H., Damongeot, F., and Walter, E. Nonlinear FDI based on state derivatives, as provided by inertial measurement units. In Proceedings of the 8th IFAC Symposium on Nonlinear control systems, Bologna, Italy, 1-3 September 2010, pp. 951-956.

136 Marzat, J., Piet-Lahanier, H., Damongeot, F., and Walter, E. Fault diagnosis for nonlinear aircraft based on control-induced redundancy. In Proceedings of the IEEE Conference on Control and fault-tolerant systems, SysTol'10, Nice, France, 6-8 October 2010, pp. 119-124.

137 Whitehead, B., Kiech, E., and Ali, M. Rocket engine diagnostics using neural networks. In Proceedings of the 26 th Joint Propulsion Conference, Orlando, 16-18 July 1990.

138 Agustin, R. M., Mangoubi, R. S., Hain, R. M., and Adams, N. J. Robust failure detection for reentry vehicle attitude control systems. J. Guid. Control Dyn., 1999, 22(6), 839-845.

139 Gorinevsky, D., Samar, S., Bain, J., and Aaseng, G. Integrated diagnostics of rocket flight control. In Proceedings of the 2005 IEEE Aerospace Conference, Big Sky, USA, 5-12 March 2005, pp. 3831-3842.

140 Ellsworth, J. C. and Whitmore, S. A. Reentry air data system for a sub-orbital spacecraft based on X-34 design. In Proccedings of the 45th AIAA Aerospace Sciences Meeting and Exhibition, Reno, USA, 8-11 January 2007.

141 Barta, C., Melendez, J., and Colomer, J. Off line diagnosis of Ariane flights using PCA. Space Technol., 2007, 27(2-3), 99-106.

142 Falcoz, A., Henry, D., and Zolghadri, A. A nonlinear fault identification scheme for reusable launch vehicles control surfaces. Int. Rev. Aerosp. Engng, 2008, 1(6), 492-503.

143 Falcoz, A., Henry, D., and Zolghadri, A. Robust fault diagnosis for atmospheric reentry vehicles: a case study. IEEE Trans. Syst. Man Cybernet. Part A: Syst. Humans, 2010, 40(5), 886-899.
144 Mehra, R., Rago, C., and Seereeram, S. Autonomous failure detection, identification and fault-tolerant estimation with aerospace applications. In Proceedings of the 1998 IEEE Aerospace Conference, vol. 2, Snowmass, USA, 21-28 March 1998, pp. 133-138.

145 Fujimaki, R., Yairi, T., and Machida, K. An approach to spacecraft anomaly detection problem using kernel feature space. Proceedings of the 11th ACM SIGKDD International Conference on Knowledge discovery in data mining, 21-24 August 2005, pp. 401-410.

146 Zhang, Q., Campillo, F., Cerou, F., and Legland, F. Nonlinear system fault detection and isolation based on bootstrap particle filters. In Proceedings of the IEEE Conference on Decision and control and European control conference, Seville, Spain, 12-15 December 2005, pp. 3821-3826.

147 Xiong, K., Chan, C. W., and Zhang, H. Y. Detection of satellite attitude sensor faults using the UKF. IEEE Trans. Aerosp. Electron. Syst., 2007, 43(2), 480-491.

148 Williamson, W. R., Speyer, J. L., Dang, V. T., and Sharp, J. Fault detection for deep space satellites. J. Guid. Control Dyn., 2009, 32(5), 1570-1584.

149 Jiang, T., Khorasani, K., and Tafazoli, S. Parameter estimation-based fault detection, isolation and recovery for nonlinear satellite models. IEEE Trans. Control Syst. Technol., 2008, 16(4), 799-808.

150 Henry, D. Fault diagnosis of microscope satellite thrusters using $\mathcal{H}_{\infty} / \mathcal{H}_{-}$filters. J. Guid. Control Dyn., 2008, 31(3).

151 Tudoroiu, N. and Khorasani, K. Satellite fault diagnosis using a bank of interacting Kalman filters. IEEE Trans. Aerosp. Electron. Syst., 2008, 43(4), 1334-1350.

152 Talebi, H. A., Khorasani, K., and Tafazoli, S. A recurrent neural-network-based sensor and actuator fault detection and isolation for nonlinear systems with application to the satellite's attitude control subsystem. IEEE Transactions on Neural Networks., 2009, 20(1), 45-60.

153 Patton, R. J., Uppal, F. J., Simani, S., and Polle, B. Robust FDI applied to thruster faults of a satellite system. In Proceedings of the 17th IFAC Symposium on Automatic control and aerospace, Toulouse, France, 25-29 June 2007.

154 Henry, D., Simani, S., and Patton, R. J. Fault detection and diagnosis for aeronautic and aerospace missions. In Fault tolerant flight control, Vol. 399 of Lecture Notes in Control and Information Sciences (Eds C. Edwards, T. Lombaerts and H. Smaili), 2010, pp. 91-128 (Springer Verlag, Berlin/Heidelberg).

155 Baldi, P., Castaldi, P., Simani, S., and Bertoni, G. Fault diagnosis and control reconfiguration for satellite reaction wheels. In Proceedings of the IEEE Conference on Control and fault-tolerant systems, SysTol'10, Nice, France, 6-8 October 2010, pp. 143-146.

156 Alwi, H., Edwards, C., and Marcos, A. FDI for a Mars orbiting satellite based on a sliding mode observer scheme. In Proceedings of the IEEE 
Conference on Control and fault-tolerant systems, SysTol'10, Nice, France, 6-8 October 2010.

157 Hull, D. G. Fundamentals of airplane flight mechanics, 2007 (Springer-Verlag, New York).

158 Stengel, R. F. Flight dynamics, 2004 (Princeton University Press).

159 Stevens, B. L. and Lewis, F. L. Aircraft control and simulation, 2003 (Wiley, New York).

160 Etkin, B. and Reid, L. D. Dynamics of flight: stability and control, 1996 (Wiley, New York).

161 Isidori, A. Nonlinear control systems: an introduction, 1995 (Springer-Verlag, Berlin-Heidelberg).

162 Board USNTS. Aircraft Accident Report: American Airlines, Inc., DC-10-10, N110AA, Chicago-O'Hare International Airport, Chicago, IL, May 251979. National Transportation Safety Board, USA.

163 Maciejowski, J. M. and Jones, C. N. MPC fault-tolerant flight control case study: Flight 1862. In Proceedings of the 5th IFAC Symposium on Fault detection, supervision and safety of technical processes, Washington D.C., 9-11 June USA 2003.

164 Reveley, M. S., Briggs, J. L., Evans, J. K., Jones, S. M., Kurtoglu, T., Leone, K. M., et al. Commercial aircraft integrated vehicle health management study, 2010 (NASA, TM-215808).

165 Lawrence, A. Modern inertial technology: navigation, guidance, and control, 1998 (Springer-Verlag, BerlinHeidelberg).

166 Barbour, N. and Schmidt, G. Inertial sensor technology trends. IEEE Sensors J., 2001, 1 (4), 332-339.

167 Merhav, S. Aerospace sensor systems and applications, 1996 (Springer-Verlag, New York).

168 Balaban, E., Saxena, A., Bansal, P., Goebel, K. F., and Curran, S. Modelling, detection, and disambiguation of sensor Faults for aerospace applications. IEEE Sensors J., 2009, 9(12), 1907-1917.

169 Stengel, R. F. and Handelman, D. Combining expert system and analytical redundancy concepts for fault-tolerant flight control. J. Guid. Control Dyn., 1989, 12, 39-45.

170 Marzat, J., Piet-Lahanier, H., Damongeot, F., and Walter, E. Control-based fault detection and isolation for autonomous aircraft. Proc. IMechE, Part G: J. Aerospace Engineering, 2011, in press.

171 Angeli, C. and Chatzinikolaou, A. On-line fault detection techniques for technical system: a survey. Int. J. Comput. Sci. Appl., 2004, 1(1), 12-30.

172 Maurya, M. R., Rengaswamy, R., and Venkatasubramanian, V. Fault diagnosis using dynamic trend analysis: a review and recent developments. Engng Appl. Artif. Intel., 2007, 20(2), 133-146.

173 Panati, A. and Dupré, D. T. Causal Simulation and Diagnosis of Dynamic Systems. In $A I^{*} I A$ 2001: Advances in artificial intelligence, Vol. 2175 of Lecture Notes in Computer Science (Ed. F. Esposito), 2001, pp. 135-146.

174 Montmain, J. and Gentil, S. Dynamic causal model diagnostic reasoning for online technical process supervision. Automatica, 2000, 36(8), 1137-1152.

175 Patton, R. J., Lopez-Toribio, C. J., and Uppal, F. J. Artificial intelligence approaches to fault diagnosis for dynamic systems. Int. J. Appl. Math. Comput. Sci., 1999, 9(3), 471-518.

176 Shin, H. J., Eom, D. H., and Kim, S. S. One-class support vector machines: an application in machine fault detection and classification. Comput. Ind. Engng, 2005, 48(2), 395-408.

177 Mahadevan, S. and Shah, S. L. Fault detection and diagnosis in process data using one-class support vector machines. J. Process Control, 2009, 19(10), 1627-1639.

178 Chandola, V., Banerjee, A., and Kumar, V. Anomaly detection: a survey. ACM Comput. Surveys, 2009, 41(3), 1-58.

179 Jain, A. K., Duin, R. P. W., and Mao, J. Statistical pattern recognition: a review. IEEE Trans. Pattern Anal. Mach. Intel., 2000, 22(1), 4-37.

180 Zhang, G. P. Neural networks for classification: a survey. IEEE Trans. Syst. Man Cybernet. Part C: Applic. Rev., 2000, 30(4), 451-462.

181 Sorsa, T., Koivo, H. N., and Koivisto, H. Neural networks in process fault diagnosis. IEEE Trans. Syst. Man Cybernet., 1991, 21(4), 815-825.

182 Patton, R. J., Chen, J., and Siew, T. M. Fault diagnosis in nonlinear dynamic systems via neural networks. In Proceedings of the International Conference on Control, vol. 2, Coventry, UK, 21-24 March 1994, pp. 1346-1351.

183 Frank, P. M. and Köppen-Seliger, B. Fuzzy logic and neural network applications to fault diagnosis. Int. J. Approx. Reason., 1997, 16(1), 67-88.

184 Markou, M. and Singh, S. Novelty detection: a review - Part 1. Statistical approaches. Signal Process., 2003, 83(12), 2481-2497.

185 Gunn, S. R. Support vector machines for classification and regression. Image Speech and Intelligent Systems Research Group, University of Southampton, 1998 (ISIS technical report).

186 Györfi, L. Principles of nonparametric learning, 2002 (Springer-Verlag, New York).

187 Vapnik, V. N. An overview of statistical learning theory. IEEE Trans. Neur. Networks, 1999, 10(5), 988-999.

188 Rasmussen, C. E. and Williams, C. K. I. Gaussian processes for machine learning, 2006 (SpringerVerlag, New York).

189 Ge, M., Du, R., Zhang, G., and Xu, Y. Fault diagnosis using support vector machine with an application in sheet metal stamping operations. Mech. Syst. Signal Process., 2004, 18(1), 143-159.

190 Davy, M., Desobry, F., Gretton, A., and Doncarli, C. An online support vector machine for abnormal events detection. Signal Process., 2006, 86(8), 2009-2025.

191 Saadawia, M. and Söffker, D. SVM-based fault diagnosis system for materials change detection. In Proceedings of the 7th Workshop on Advanced control and diagnosis, Zielona Gora, Poland, 19-20 November 2009.

192 Kulkarni, S. R., Lugosi, G., and Venkatesh, S. S. Learning pattern classification - a survey. IEEE Trans. Inform. Theory, 1998, 44(6). 
193 Markou, M. and Singh, S. Novelty detection: a review - Part 2. Neural network based approaches. Signal Process., 2003, 83(12), 2499-2521.

194 Alcala, C. F. and Qin, S. J. Unified analysis of diagnosis methods for process monitoring. In Proceedings of the 7th IFAC Symposium on Fault detection, supervision and safety of technical processes, Barcelona, Spain, 1-3 July 2009, pp. 1007-1012.

195 Harkat, M. F., Mourot, G., and Ragot, J. An improved PCA scheme for sensor FDI: application to an air quality monitoring network. J. Process Control, 2006, 16(6), 625-634.

196 Tharrault, Y., Mourot, G., Ragot, J., and Maquin, D. Fault detection and isolation with robust principal component analysis. Int. J. Appl. Math. Comput. Sci., 2008, 18(4), 429-442.

197 Lee, J. M., Yoo, C. K., Choi, S. W., Vanrolleghem, P. A., and Lee, I. B. Nonlinear process monitoring using kernel principal component analysis. Chem. Engng Sci., 2004, 59(1), 223-234.

198 Lee, J. M., Yoo, C. K., and Lee, I. B. Statistical process monitoring with independent component analysis. J. Process Control, 2004, 14(5), $467-485$.

199 Li, W., Yue, H. H., Valle-Cervantes, S., and Qin, S. J. Recursive PCA for adaptive process monitoring. J. Process Control., 2000, 10(5), 471-486.

200 Wang, X., Kruger, U., and Lennox, B. Recursive partial least squares algorithms for monitoring complex industrial processes. Control Eng. Pract., 2003, 11 (6), 613-632.

201 Walter, E. and Pronzato, L. On the identifiability and distinguishability of nonlinear parametric models. Math. Comput. Simul., 1996, 42(2-3), 125-134.

202 Isermann, R. Fault diagnosis of machines via parameter estimation and knowledge processing-Tutorial paper. Automatica, 1993, 29(4), 815-835.

203 Delmaire, G., Cassar, J. P., and Staroswiecki, M. Identification and parity space techniques for failure detection in SISO systems including modelling errors. In Proceedings of the 33rd IEEE Conference on Decision and control, vol. 3, Lake Buena Vista, USA, 14-16 December 1994, pp. 2279-2285.

204 Bloch, G., Ouladsine, M., and Thomas, P. On-line fault diagnosis of dynamic systems via robust parameter estimation. Control Eng. Pract., 1995, 3(12), 1709-1717.

205 Doraiswami, R. and Stevenson, M. A robust influence matrix approach to fault diagnosis. IEEE Trans. Control Syst. Technol., 1996, 4(1), 29-39.

206 Walter, E. and Pronzato, L. Identification of parametric models from experimental data, 1997 (Springer-Verlag, Berlin-Heidelberg).

207 Jaulin, L., Kieffer, M., Didrit, O., and Walter, E. Applied interval analysis, 2001 (Springer, London).

208 Simpson, T. W., Poplinski, J. D., Koch, P. N., and Allen, J. K. Metamodels for computer-based engineering design: survey and recommendations. Eng. Comput., 2001, 17(2), 129-150.
209 Villemonteix, J., Vazquez, E., and Walter, E. Bayesian optimization for parameter identification on a small simulation budget. In Proceedings of the 15th IFAC Symposium on System identification, SYSID 2009, Saint-Malo, France, 6-8 July 2009, pp. 1603-1608.

210 Basseville, M., Abdelghani, M., and Benveniste, A. Subspace-based fault detection algorithms for vibration monitoring. Automatica, 2000, 36(1), 101-109.

211 Pekpe, K. M., Mourot, G., and Ragot, J. Subspace method for sensor fault detection and isolationapplication to grinding circuit monitoring. In Proceedings of the 11th IFAC Symposium on Automation in mining, mineral and metal processing, Nancy, France, 22-24 May 2006, pp. 47-52.

212 Puig, V. Fault diagnosis and fault tolerant control using set-membership approaches: application to real case studies. Int. J. Appl. Math. Comput. Sci., 2010, 20(4), 619-635.

213 Kieffer, M. and Walter, E. Guaranteed estimation of the parameters of nonlinear continuous-time models: contributions of interval analysis. Int. J. Adapt. Control Signal Process., 2011, 25(3), 191-207.

214 Castillo, S. M., Gelso, E. R., and Armengol, J. Constraint satisfaction techniques under uncertain conditions for fault diagnosis in nonlinear dynamic systems. In Proceedings of the 16th IEEE Mediterranean Conference on Control and automation, Ajaccio, France, 1-3 September 2008, pp. 1216-1221.

215 Ingimundarson, A., Bravo, J. M., Puig, V., Alamo, T., and Guerra, P. Robust fault detection using zonotope-based set-membership consistency test. Int. J. Adapt. Control Signal Process., 2009, 23(4), 311-330.

216 Reppa, V. and Tzes, A. Fault detection and diagnosis based on parameter set estimation. IET Control Theory Applic., 2011, 5(1), 69-83.

217 Beard, R. V. Failure accommodation in linear systems through self-reorganization. PhD Thesis, 1971 (Department of Aeronautics Astronautics, MIT, Cambridge, MA).

218 Jones, H. L. Failure detection in linear systems. $\mathrm{PhD}$ Thesis, 1973 (Deptartment Aeronautics Astronautics, MIT, Cambridge, Massachusetts).

219 Luenberger, D. G. Observers for multivariable systems. IEEE Trans. Autom. Control, 1966, 11(2), 190-197.

220 Patton, R. J. and Chen, J. Observer-based fault detection and isolation: robustness and applications. Control Eng. Pract., 1997, 5(5), 671-682.

221 Alcorta Garcia, E. and Frank, P. M. Deterministic nonlinear observer-based approaches to fault diagnosis: a survey. Control Eng. Pract., 1997, 5(5), 663-670.

222 Frank, P. M. and Ding, X. Survey of robust residual generation and evaluation methods in observerbased fault detection systems. J. Process Control, 1997, 7(6), 403-424. 
223 Zeitz, M. The extended Luenberger observer for nonlinear systems. Syst. Control Lett., 1987, 9(2), 149-156.

224 Nejjari, F., Puig, V., Giancristofaro, L., and Koehler, S. Extended Luenberger observer-based fault detection for an activated sludge process. In Proceedings of the 17th IFAC World Congress, Seoul, Korea, 6-11 July 2008, pp. 9725-9730.

225 Adjallah, K., Maquin, D., and Ragot, J. Nonlinear observer-based fault detection. In Proceedings of the 3rd IEEE Conference on Control applications, Glasgow, Scotland, 24-26 August 1994, pp. 1115-1120.

226 Chen, W., Saif, M., and Soh, Y. A variable structure adaptive observer approach for actuator fault detection and diagnosis in uncertain nonlinear systems. In Proceedings of the American Control Conference, vol. 4, Chicago, USA, 28-30 June 2000, pp. 2674-2678.

227 Xu, A. and Zhang, Q. Nonlinear system fault diagnosis based on adaptive estimation. Automatica, 2004, 40(7), 1181-1193.

$228 \mathrm{Li}$, Z. and Dahhou, B. An observers based fault isolation approach for nonlinear dynamic systems. In Proceedings of the 2nd International Symposium on Communications, control and signal processing, Marrakech, Morocco, 13-15 March 2006.

229 Zhang, X., Polycarpou, M. M., and Parisini, T. Fault diagnosis of a class of nonlinear uncertain systems with Lipschitz nonlinearities using adaptive estimation. Automatica, 2010, 46(2), 290-299.

230 Hammouri, H., Kinnaert, M., and Yaagoubi, E. H. E Observer-based approach to fault detection and isolation for nonlinear systems. IEEE Trans. Autom. Control, 1999, 44(10), 1879-1884.

231 Busvelle, E. and Gauthier, J. P. High-gain and non high-gain observers for nonlinear systems. Contemp. Trends Nonlinear Geomet. Control Theory, 2002, 257-286.

232 Besançon, G. High-gain observation with disturbance attenuation and application to robust fault detection. Automatica, 2003, 39(6), 1095-1102.

233 Andrieu, V. and Praly, L. On the existence of a Kazantzis-Kravaris/Luenberger observer. SIAM J. Control Optim., 2006, 45(2), 432-456.

234 Andrieu, V. Exponential convergence of nonlinear Luenberger observers. In Proceedings of the 49th IEEE Conference on Decision and Control, Atlanta, USA, 15-17 December 2010, pp. 2163-2168.

235 Edwards, C., Spurgeon, S. K., and Patton, R. J. Sliding mode observers for fault detection and isolation. Automatica, 2000, 36(4), 541-553.

236 Tan, C. P. and Edwards, C. Sliding mode observers for robust detection and reconstruction of actuator and sensor faults. Int. J. Robust and Nonlinear Control, 2003, 13(5), 443-463.

237 Jiang, B., Staroswiecki, M., and Cocquempot, V. Fault estimation in nonlinear uncertain systems using robust/sliding-mode observers. IEE Proc. Control Theory and Applic., 2004, 151(1), 29-37.
238 Takagi, T. and Sugeno, M. Fuzzy identification of systems and its applications to modelling and control. IEEE Trans. Syst. Man Cybernet., 1985, 15, 116-132.

239 Ichtev, A., Hellendoorn, J., and Babuska, R. Fault detection and isolation using multiple TakagiSugeno fuzzy models. In Proceedings of the 10th IEEE International Conference on Fuzzy systems, vol. 3, Melbourne, Australia, 2-5 December 2001, pp. 1498-1502.

240 Ichalal, D., Marx, B., Ragot, J., and Maquin, D. Fault diagnosis for Takagi-Sugeno nonlinear systems. In Proceedings of the 7th IFAC Symposium on Fault detection, supervision and safety of technical processes, Barcelona, Spain, 1-3 July 2009, pp. 504-509.

241 Kalman, R. E. A new approach to linear filtering and prediction problems. J. Basic Engng, 1960, 82(1), 35-45.

242 Mehra, R. K. and Peschon, J. An innovations approach to fault detection and diagnosis in dynamic systems. Automatica, 1971, 7(5), 637-640.

243 Willsky, A. Detection of abrupt changes in dynamic systems. In Detection of abrupt changes in signals and dynamical systems vol. 77 (Eds M. Basseville, A. Benveniste), 1986, pp. 27-49 (Springer-Verlag, Berlin).

244 Nikoukhah, R. Innovations generation in the presence of unknown inputs: application to robust failure detection. Automatica, 1994, 30(12), 1851-1867.

245 Zolghadri, A. An algorithm for real-time failure detection in Kalman filters. IEEE Trans. Autom. Control, 1996, 41(10), 1537-1539.

246 Hanlon, P. D. and Maybeck, P. S. Multiple-model adaptive estimation using a residual correlation Kalman filter bank. IEEE Trans. Aerosp. Electron. Syst., 2000, 36(2), 393-406.

247 Blom, H. A. P. and Bar-Shalom, Y. The interacting multiple model algorithm for systems with Markovian switching coefficients. IEEE Trans. Autom. Control, 1988, 33(8), 780-783.

$248 \mathbf{R u}, \mathbf{J}$. and $\mathbf{L i}, \mathbf{R}$. Interacting multiple model algorithm with maximum likelihood estimation for FDI. In Proceedings of the IEEE International Symposium on Intelligent control, Houston, USA, 5-8 October 2003, pp. 661-666.

249 Hocine, A., Maquin, D., and Ragot, J. Finite memory observer for switching systems: Application to diagnosis. In Proceedings of the 16th IFAC World Congress, Prague, Czech Republic, 3-8 July 2005, pp. 406-411.

250 Chang, C. T. and Chen, J. W. Implementation issues concerning the EKF-based fault diagnosis techniques. Chem. Engng Sci., 1995, 50(18), 2861-2882.

251 Julier, S. J. and Uhlmann, J. K. Unscented filtering and nonlinear estimation. Proc. IEEE, 2004, 92(3), 401-422.

252 Cork, L. and Walker, R. Sensor fault detection for UAVs using a nonlinear dynamic model and the IMM-UKF algorithm. In Proceedings of the Conference on Information, decision and control, 
Adelaide, Queensland, 12-14 February 2007, pp. 230-235.

253 Xiong, K., Chan, C. W., and Zhang, H. Y. Unscented Kalman filter for fault detection. In Proceedings of the 16th IFAC World Congress, Prague, Czech Republic, 3-8 July 2005, pp. 113-118.

254 Andrieu, C., Doucet, A., Singh, S. S., and Tadic, V. B. Particle methods for change detection, system identification, and control. Proc. IEEE, 2004, 92(3), 423-438.

255 Li, P. and Kadirkamanathan, V. Particle filtering based likelihood ratio approach to fault diagnosis in nonlinear stochastic systems. IEEE Trans. Syst. Man Cybernet. Part C Applic. Rev., 2001, 31(3), 337-343.

256 Verma, V., Gordon, G., Simmons, R., and Thrun, S. Real-time fault diagnosis. IEEE Robot. Autom. Mag., 2004, 11 (2), 56-66.

257 Wang, X. and Syrmos, V. L. Interacting multiple particle filters for fault diagnosis of nonlinear stochastic systems. In Proceedings of the American Control Conference, Seattle, USA, 11-13 June 2008, pp. 4274-4279.

258 Raïssi, T., Videau, G., and Zolghadri, A. Interval observer design for consistency checks of nonlinear continuous-time systems. Automatica, 2010, 46(3), 518-527.

259 Puig, V., Quevedo, J., Escobet, T., Nejjari, F., and de las Heras, S. Passive robust fault detection of dynamic processes using interval models. IEEE Trans. Control Syst. Technol., 2008, 16(5), 1083-1089.

260 Patton, R. J. and Chen, J. A review of parity space approaches to fault diagnosis. In Proceedings of the 1st IFAC Symposium on Fault detection, supervision and safety of technical processes, BadenBaden, Germany, 10-13 September 1991, pp. 65-81.

261 Gertler, J. J. and Monajemy, R. Generating directional residuals with dynamic parity relations. Automatica, 1995, 31(4), 627-635.

262 Patton, R. J. and Chen, J. Robust fault detection using eigenstructure assignment: a tutorial consideration and some new results. In Proceedings of the 30th IEEE Conference on Decision and control, Brighton, 11-12 December 1991, pp. 2242-2247.

263 Magni, J. F. and Mouyon, P. On residual generation by observer and parity space approaches. IEEE Trans. Autom. Control, 1994, 39(2), 441-447.

264 Gertler, J. J. All linear methods are equal - and extendible to (some) nonlinearities. International J. Robust Nonlinear Control, 2002, 12(8), 629-648.

265 Maquin, D., Cocquempot, V., Cassar, J. P., Staroswiecki, M., and Ragot, J. Generation of analytical redundancy relations for FDI purposes. In IEEE Symposium on Diagnostics for electrical machines, power electronics and drive, SDEMPED'97, Carry-le Rouet, France, September 1997, pp. 270-276.

266 Medvedev, A. Fault detection and isolation by a continuous parity space method. Automatica, 1995, 31(7), 1039-1044.
267 Staroswiecki, M. and Comtet-Varga, G. Analytical redundancy relations for fault detection and isolation in algebraic dynamic systems. Automatica, 2001, 37(5), 687-699.

268 Shumsky, A. Redundancy relations for fault diagnosis in nonlinear uncertain systems. Int. J. Appl. Math. Comput. Sci., 2007, 17(4), 477-489.

269 Hammouri, H., Kabore, P., and Kinnaert, M. A geometric approach to fault detection and isolation for bilinear systems. IEEE Trans. Autom. Control, 2001, 46(9), 1451-1455.

270 Leuschen, M. L., Walker, I. D., and Cavallaro, J. R. Fault residual generation via nonlinear analytical redundancy. IEEE Trans. Control Syst. Technol., 2005, 13(3), 452-458.

271 Massoumnia, M. A. A geometric approach to the synthesis of failure detection filters. IEEE Trans. Autom. Control, 1986, 31(9), 839-846.

272 Patton, R. J. and Chen, J. On eigenstructure assignment for robust fault diagnosis. Int. J. Robust Nonlinear Control, 2000, 10(14), 1193-1208.

273 Gertler, J. J. and Kunwer, M. M. Optimal residual decoupling for robust fault diagnosis. Int. J. Control, 1995, 61(2), 395-422.

274 Watanabe, K. and Himmelblau, D. M. Instrument fault detection in systems with uncertainties. Int. J. Syst. Sci., 1982, 13(2), 137-158.

275 Gaddouna, B., Maquin, D., and Ragot, J. Fault detection observers for systems with unknown inputs. In Proceedings of the 2nd IFAC Symposium on Fault detection, supervision and safety of technical processes, Espoo, Finland, 13-16 June 1994.

276 Chen, J., Patton, R. J., and Zhang, H. Y. Design of unknown input observers and robust fault detection filters. Int. J. Control, 1996, 63(1), 85-105.

277 Chen, W. and Saif, M. Fault detection and isolation based on novel unknown input observer design. In Proceedings of the American Control Conference, Minneapolis, USA, 14-16 June 2006, pp. 5129-5134.

278 Koenig, D. Observer design for unknown input nonlinear descriptor systems via convex optimization. IEEE Trans. Autom. Control, 2006, 51(6), 1047-1052.

279 Pertew, A. M., Marquez, H. J., and Zhao, Q. LMIbased sensor fault diagnosis for nonlinear Lipschitz systems. Automatica, 2007, 43(8), 1464-1469.

280 Seliger, R. and Frank, P. M. Fault-diagnosis by disturbance decoupled nonlinear observers. In Proceedings of the 30th IEEE Conference on Decision and control, vol. 3, Brighton, UK, 11-12 December 1991, pp. 2248-2253.

281 Martinez-Guerra, R. and Diop, S. Diagnosis of nonlinear systems using an unknown-input observer: An algebraic and differential approach. IEE Proc. Control Theory Applic., 2004, 151 (1), 130-135.

282 Barbot, J. P., Boutat, D., and Floquet, T. An observation algorithm for nonlinear systems with unknown inputs. Automatica, 2009, 45(8), 1970-1974. 
283 Hou, M. and Patton, R. An LMI approach to $\mathcal{H}_{-} /$ $\mathcal{H}_{\infty}$ fault detection observers. In Proceedings of the UKACC International Conference on Control, pp. 305-310, Exeter, UK, 2-5 September 1996.

284 Rank, M. L. and Niemann, H. H. Norm based design of fault detectors. Int. J. Control, 1999, 72(9), 773-783.

285 Henry, D. and Zolghadri, A. Design and analysis of robust residual generators for systems under feedback control. Automatica, 2005, 41(2), 251-264.

286 Zhong, M., Ding, S. X., Lam, J., and Wang, H. An LMI approach to design robust fault detection filter for uncertain LTI systems. Automatica, 2003, 39(3), 543-550.

287 Stoustrup, J. and Niemann, H. H. Fault estimation - a standard problem approach. Int. J. Robust Nonlinear Control, 2002, 12(8), 649-673.

288 De Persis, C. and Isidori, A. A geometric approach to nonlinear fault detection and isolation. IEEE Trans. Autom. Control, 2001, 46(6), 853-865.

289 Bokor, J. and Szabó, Z. Fault detection and isolation in nonlinear systems. Ann. Rev. Control, 2009, 33(2), 113-123.

290 Fliess, M., Join, C., and Sira-Ramirez, H. Robust residual generation for linear fault diagnosis: An algebraic setting with examples. Int. J. Control, 2004, 77(14), 1223-1242.

291 Berdjag, D., Christophe, C., Cocquempot, V., and Jiang, B. Nonlinear model decomposition for robust fault detection and isolation using algebraic tools. Int. J. Innov. Comput. Inform. Control, 2006, 2(6), 1337-1354.

292 Edelmayer, A., Bokor, J., Szabo, Z., and Szigeti, F. Input reconstruction by means of system inversion: A geometric approach to fault detection and isolation in nonlinear systems. Int. J. Appl. Math. Comput. Sci., 2004, 14(2), 189-200.

293 Edelmayer, A., Bokor, J., and Szabó Z Inversionbased residual generation for robust detection and isolation of faults by means of estimation of the inverse dynamics in linear dynamical systems. Int. J. Control, 2009, 82(8), 1526-1538.

294 Hirschorn, R. Invertibility of multivariable nonlinear control systems. IEEE Trans. Autom. Control, 1979, 24(6), 855-865.

295 Campbell, S. L. and Nikoukhah, R. Auxiliary signal design for failure detection, 2004 (Princeton University Press, Princeton).

296 Niemann, H. H. Active fault diagnosis in closedloop uncertain systems. In Proceedings of the 6th IFAC Symposium on Fault detection supervision ans safety for technical processes, Beijing, China, 30 August-1 September 2006, pp. 631-636.

297 Ashari, A. E., Nikoukhah, R., and Campbell, S. L. Feedback in active fault detection. In Proceedings of the 15th IFAC Symposium on System identification, St Malo, 6-8 July 2009, pp. 192-196.

298 Niemann, H. H. and Stoustrup, J. Active fault diagnosis by temporary destabilization. In Proceedings of the 6th IFAC Symposium on Fault detection supervision ans safety for technical processes,
Beijing, China, 30 August-1 September 2006, pp. 607-612.

299 Jacobson, C. A. and Nett, C. N. An integrated approach to controls and diagnostics using the four-parameter controller. IEEE Control Syst. Mag., 1991, 11(6), 22-29.

300 Ding, S. X. Integrated design of feedback controllers and fault detectors. Ann. Rev. Control, 2009, 33(2), 124-135.

301 Niemann, H. H. and Stoustrup, J. Robust fault detection in open loop vs. closed loop. In Proceedings of the 36th IEEE Conference on Decision and control, vol. 5, San Diego, 10-12 December 1997, pp. 4496-4497.

302 Baikeche, H., Marx, B., Maquin, D., and Ragot, J. On parametric and nonparametric fault detection in linear closed-loop systems. In Proceedings of the 4th Workshop on Advanced control and diagnosis, Nancy, 16-17 November 2006.

303 Basseville, M. Information criteria for residual generation and fault detection and isolation. Automatica, 1997, 33(5), 783-803.

304 Gertler, J. J. and Luo, Q. Robust isolable models for failure diagnosis. AIChE J., 1989, 35(11), 1856-1868.

305 Basseville, M. Detecting changes in signals and systems-a survey. Automatica, 1988, 24(3), 309-326.

306 Benveniste, A., Basseville, M., and Moustakides, G. The asymptotic local approach to change detection and model validation. IEEE Trans. Autom. Control, 1987, 32(7), 583-592.

307 Basseville, M. On-board component fault detection and isolation using the statistical local approach. Automatica, 1998, 34(11), 1391-1415.

308 Pukelsheim, F. The three sigma rule. Am. Statist., 1994, 48(2), 88-91.

309 Emami-Naeini, A., Akhter, M. M., and Rock, S. M. Effect of model uncertainty on failure detection: the threshold selector. IEEE Trans. Autom. Control, 1988, 33(12), 1106-1115.

310 Ding, S. X., Zhang, P., Frank, P. M., and Ding, E. L. Threshold calculation using LMI-technique and its integration in the design of fault detection systems. In Proceedings of the 42nd IEEE Conference on Decision and control, vol. 1, Maui, USA, IEEE, 9-12 December 2003, pp. 469-474.

311 Gosset, W. S. The probable error of a mean. Biometrika., 1908, 6(1), 1-25.

312 Neyman, J. and Pearson, E. S. On the problem of the most efficient tests of statistical hypotheses. Philos. Trans. R. Soc. Lond. A, 1933, 231, 289-337.

313 Weyer, E., Sangho, K., and Campi, M. C. A randomised subsampling method for change detection. In Proceedings of the 7th IFAC Symposium on Fault detection, supervision and safety of technical processes, Barcelona, Spain, 1-3 July 2009, pp. 289-294.

314 Benedettini, O., Baines, T. S., Lightfoot, $\mathbf{H}$. W., and Greenough, R. M. State-of-the-art in integrated vehicle health management. Proc. IMechE, Part G: J. Aerospace Engineering, 2009, 223(2), 157-170.

315 Takats, I. J. and Chenoweth, C. C. Multiple-voting fault detection system for flight critical actuation control systems, US Patent 5,274,554, 1998. 
316 Tomlinson, L. R. and Freeman, R. E. Signal selection and fault detection apparatus and method, US Patent 5,710,776, 1998.

317 Sr, J. M. U. and Hood, M. B. Method and system for in-flight fault monitoring of flight control actuators, US Patent 6,622,972, 2003.

318 Beckman-Kohlmeier, C. and Kessler, J. System and method for detecting faults in an aircraft electrical power system, EP Patent 1,501,167, 2005.

319 Richter, M. and Fleddermann, A. Fault-tolerant actuating system for adjusting flaps of an aircraft, comprising adjustment kinematics with a fixed pivot, and a method for monitoring an actuating system, US Patent App. 12/991,174, 2009.

320 Cheriere, V. and Girio, J. A. D. S. Method and device for fault auto-detection in an on-board system, US Patent App. 12/476,436, 2009.

321 Durou, O., Godet, V., Mangane, L., Pérarnaud, D., and Roques, R. Hierarchical fault detection, isolation and recovery applied to COF and ATV avionics. Acta Astronaut., 2002, 50(9), 547-556.

322 Charmeau, M. C., Bossard, F., Caranana, A., Lamy, A., and Laurichesse, D. CNES R\&D studies on autonomous satellites. In Proceedings of the 6th International Symposium on Artificial intelligence and robotics \& automation in space, Quebec, Canada, 18-22 July 2001.

323 Baroth, E., Powers, W. T., Fox, J., Prosser, B., Pallix, J., Schweikard, K., et al. IVHM (Integrated Vehicle Health Management) techniques for future space vehicles. In Proceedings of the 37th AIAA Joint Propulsion Conference and Exhibit, Salt Lake City, USA, 8-11 July 2001.

324 Sabatier, D., Dellandrea, B., and Chemouil, D. FDIR strategy validation with the B method. In Proceedings of the International Space System Engineering Conference, Palma de Majorca, Spain, 27-30 May 2008.

325 Guiotto, A., Martelli, A., and Paccagnini, C. SMARTFDIR: Use of artificial intelligence in the implementation of a satellite FDIR. In Proceedings of the International Space System Engineering Conference, Prague, Czech Republic, 12-14 May 2003, pp. 71-82.

326 Katoen, J. P. and Noll, T. Trustworthy aerospace systems. Public Service Rev. Eur. Sci. Technol., 2011, 11, 204-205.

327 Schwabacher, M., Samuels, J., and Brownston, L. The NASA integrated vehicle health management technology experiment for X-37. In Proceedings of the SPIE AeroSense 2002 Symposium, Orlando, USA, 1-5 April 2002.

328 Ferrel, B., Lewis, M., Perotti, J., Oostdyk, R., Goerz, J., and Brown, B. Lessons learned on implementing fault detection, isolation and recovery in a ground launch environment. In Proceedings of the AIAA Aerospace Conference, Atlanta, USA, 20-22 April 2010.

329 Goupil, P. and Puyou, G. A high fidelity AIRBUS benchmark for system fault detection and isolation and flight control law clearance. In Proceedings of

the 4th European Conference for Aero-Space Sciences, EUCASS 2011, St-Petersburg, Russia, 4-8 July 2011.

330 Feather, M. S. and Markosian, L. Z. Towards certification of a space system application of fault detection and isolation. In Proceedings of the 2008 International Conference on Prognostics and health management, Denver, USA, 6-9 October 2008.

331 Gao, Z. and Ding, S. X. Actuator fault robust estimation and fault-tolerant control for a class of nonlinear descriptor systems. Automatica, 2007, 43(5), 912-920.

332 Marzat, J., Walter, E., Piet-Lahanier, H., and Damongeot, F. Automatic tuning via Krigingbased optimization of methods for fault detection and isolation. In Proceedings of the IEEE Conference on Control and fault-tolerant systems, SysTol'10, Nice, France, 6-8 October 2010, pp. 505-510.

333 Marzat, J., Walter, E., and Piet-Lahanier, H. Minmax hyperparameter tuning with application to fault detection. In Proceedings of the 18th IFAC World Congress, Milan, Italy, 28 August-2 September 2011, pp. 12904-12909.

\section{APPENDIX}

\section{Notation}

$\mathbf{1}_{n}$

A, B, C

$c_{(.)}$

$\mathbf{f}, \mathbf{G}$, and $\mathbf{h}$

$\mathbf{f}_{\text {aero }}, \mathbf{f}_{\mathrm{g}}$, and $\mathbf{f}_{\text {prop }}$

I

K

L

$L_{\text {aero }}, M_{\text {aero }}, N_{\text {aero }}$

$L_{\text {naero }}, M_{\text {naero }}, N_{\text {naero }}$

$m$

Q

$\mathbf{r}$

$r$

$\bar{r}$

$s_{\text {ref }}$ and $l_{\text {ref }}$

$\mathbf{u}$

$\mathbf{v}_{\mathrm{m}}=[\dot{x}, \dot{y}, \dot{z}]^{\mathrm{T}}$

$\mathbf{v}_{\mathrm{bm}}=\left[v_{\mathrm{bx}}, v_{\mathrm{by}}, v_{\mathrm{bz}}\right]^{\mathrm{T}}$

$\mathbf{w}_{\mathrm{d}}$

$\mathbf{w}_{\mathrm{f}}$ $n \times n$ identity matrix state, input, and output matrices of a linear model aerodynamic coefficient state and output mappings of a non-linear model aerodynamic, gravitational, and propulsion forces (N) inertia matrix $\left(\mathrm{kg} \cdot \mathrm{m}^{2}\right)$ state feedback gain Luenberger observer gain aerodynamic moments $(\mathrm{N} \cdot \mathrm{m})$ non-aerodynamic moments $(\mathrm{N} \cdot \mathrm{m})$ mass (kg) dynamic pressure $\left(\mathrm{N} / \mathrm{m}^{2}\right)$ vector of residuals scalar residual mean of $r$ reference surface, $\mathrm{m}^{2}$, and length (m) input vector velocity in inertial frame ( $\mathrm{m} / \mathrm{s})$ velocity in body frame $(\mathrm{m} / \mathrm{s})$ disturbance vector fault vector 


\begin{abstract}
$\mathbf{X}$
$\mathbf{x}_{\mathrm{m}}=[x, y, z]^{\mathrm{T}}$

$\mathbf{x}_{\mathrm{bm}}=\left[x_{\mathrm{b}}, y_{\mathrm{b}}, z_{\mathrm{b}}\right]^{\mathrm{T}}$

$\mathbf{y}$
\end{abstract}

state vector

position in inertial frame (m)

position in body frame $(\mathrm{m})$

output vector $\alpha$

$\beta$

$\boldsymbol{\omega}=[p, q, r]^{\mathrm{T}}$

$[\varphi, \theta, \psi]^{\mathrm{T}}$ angle of attack (rad) sideslip angle (rad) angular velocity ( $\mathrm{rad} / \mathrm{s})$ orientation (rad) 